\title{
¿Se considera Nicaragua vecino y actor internacional políticamente conflictivo para Costa Rica?
}

\section{Is Nicaragua considered an international politically- conflictive neighbor and actor for Costa Rica?}

\author{
Fabiana Jenkins Arias \\ Universidad Nacional, Sede Central \\ Heredia, Costa Rica \\ fabi_jenk@hotmail.com
}

Resumen: Para el 2012 los roces entre Costa Rica y Nicaragua se incrementan en torno al litigio fronterizo sobre Isla Calero. El gobierno nicaragüense emite una serie de amenazas sobre la posibilidad de "recuperar" territorio bajo jurisdicción costarricense así como zonas en disputa, y crea un clima de incertidumbre para Costa Rica. Producto de lo anterior, en el presente documento se analiza la forma en que un medio de comunicación costarricense dio tratamiento a la información y expuso a la ciudadanía el desarrollo del litigio para el 2013. Para ello se desarrolla un análisis de contenido, el cual arroja como resultado que en Costa Rica se percibe a Nicaragua como vecino conflictivo, ajustándose a la construcción de Estado diseñada por la teoría neorrealista, hipótesis planteada para el desarrollo de este artículo. Finalmente, se analizan las implicaciones que ese imaginario social de conflictividad conlleva para las relaciones exteriores entre ambos países.

Palabras clave: Costa Rica, Nicaragua, litigio, Neorrealismo, prensa.

Abstract: By 2012, conflict between Costa Rica and Nicaragua increased due to the border dispute over Isla Calero. The Nicaraguan government expressed a series of threats on the possibility of 'recovering' territory under Costa 
Rican jurisdiction as well as zones in dispute, and created a climate of uncertainty for Costa Rica. This document presents an analysis of the way in which a Costa Rican communication means managed the information and displayed the development of the litigation for 2013. For this purpose, an analysis of content was made, which produces the result that, in Costa Rica, Nicaragua is perceived as a problematic neighbor, matching the construction of the State designed by the neo-realist theory, a hypothesis raised for the development of this article. Finally, the implications that this social construct of conflict entails for the relationship between these two countries.

Keywords: Costa Rica, Nicaragua, dispute, Neo -realism, press.

\section{Introducción}

D ara el 2013, las relaciones diplomáticas entre Costa Rica y Nicaragua se habían caracterizado por el aumento de tensiones respecto de la fijación de límites, tanto marítimos como territoriales, en la línea fronteriza entre ambas naciones. Este litigio limítrofe es un tópico que se remonta desde hace casi dos siglos, cuando ambos países centroamericanos consiguieron su independencia de la Corona Española. Sin embargo, desde el 2010 se viene experimentando un mayor deterioro en las relaciones bilaterales entre estas naciones: primero, con la demanda llevada a la Corte Internacional de Justicia, ese mismo año, donde se le acusaba a Nicaragua de invasión a territorio costarricense y, posteriormente, con la demanda hacia Costa Rica por daños ambientales en la zona fronteriza.

Aunado a ello, para el 2013 el gobierno nicaragüense inicia negociaciones sobre territorios de ultramar para la explotación petrolera, con países como Estados Unidos y España. Estos territorios corresponden a las áreas marítimas que le ganaron a Colombia ante la CIJ tras 12 años de litigio. No obstante, Costa Rica considera que de esos territorios que se mantienen en negociación, 18 áreas en el Pacífico y 55 en el Caribe le corresponden (Sequeira, 2013). A razón de ello, las tensiones en este sentido se intensificaron y se mantiene el constante clima de conflicto, acusaciones y protesta entre ambos países.

Adicionalmente, Nicaragua ha amenazado a Costa Rica de reclamar la provincia guanacasteca -durante el 33 Aniversario de su Fuerza Naval- considerándolo un hecho digno de llevar ante la CIJ. Ante ello, el gobierno costarricense señala como negativas las políticas expansionistas de su vecino, al llevar el caso ante la Organización de las Naciones Unidas (ONU) (Mata, 2013). Asimismo, manifiesta 
que llevará el caso sobre los territorios marítimos -que indica le correspondenante la Corte Internacional de Justicia.

Las diferencias territoriales entre Nicaragua y Costa Rica van más allá del litigio en torno a Isla Calero, pues amplían al hecho de que no existe una división clara de los territorios marítimos, los cuales representan un área considerablemente grande y rica en recursos naturales. Finalmente, el existente clima de conflicto se ha visto incrementado con la idea de Ortega de reclamar la provincia de Guanacaste, lo que ha despertado un clima de alarma en la sociedad costarricense, la opinión pública y los medios de comunicación. Esto lleva a las siguientes interrogantes:

- ¿Cómo está percibiendo la sociedad costarricense las amenazas por parte del gobierno nicaragüense?

- ¿Qué están vendiendo los medios de comunicación costarricense?

- ¿Cuál es la forma en que comunican el conflicto desde perspectivas teóricas de las relaciones internacionales

El presente documento procura analizar el contenido expuesto por la prensa costarricense, ante esta problemática de tal relevancia para ambos estados centroamericanos. El fin es identificar la evolución del conflicto, la cobertura que se le ha dado y cuál ha sido la retórica e intención a la hora de exponer la situación ante la sociedad civil. El objetivo base es determinar si en Costa Rica se vende la idea de Nicaragua como actor, cuya estrategia de operación en política exterior se basa en la lógica de real polik ${ }^{1}$ y de poder duro ${ }^{2}$. Es decir, se espera determinar si se percibe a Nicaragua como país conflictivo, racional y que pone sus intereses por encima de sus vecinos, con tal de cerciorar su propia seguridad. Para ello se utiliza la teoría de relaciones internacionales: Neorrealismo o Realismo Estructural, la cual se explica detalladamente en el siguiente apartado.

En este sentido, la importancia de desarrollar análisis de contenido consiste en que es una herramienta que permite conocer las intenciones de actores claves -como gobiernos, líderes políticos y líderes de opinión- lo cual permite tener

1 Término acuñado por el alemán Otto von Bismarck en el siglo XX. En el campo de las relaciones internacionales expone cómo los Estados direccionan su política exterior en función del interés nacional y de poder, y no basada en consideraciones idealistas o amistosas. Ha sido utilizado por figuras como Nicolás Maquiavelo y Sun Tzu.

2 Término utilizado en relaciones internacionales para hacer referencia a la capacidad de ciertos Estados, para persuadir el accionar e intereses de otros Estados, utilizando medios militares y económicos con el fin de alcanzar sus objetivos nacionales. 
ventajas y mayores insumos para la prospección de escenarios y la elaboración de estrategias (de negociación, defensa, etc.) con respecto a otros actores. Asimismo, ofrece una herramienta de análisis para conocer al enemigo o a países con los que se mantienen disputas, al permitir así coordinar de manera racional la toma de posiciones políticas sobre un actor o coyuntura específica. Ya lo decía Sun Tzu: "conócete a ti mismo y conoce a tu enemigo y en cien batallas nunca saldrás derrotado" (s.f., p.9). Esto no solo aplica para los enemigos, sino para cualquier actor sobre el que se desee tener ventaja en el sistema internacional.

El análisis de la información que emiten los medios de prensa también es sumamente valioso en el estudio de comunicación política, ya que estos generan opinión pública y crean gobernanza ${ }^{3}$ sobre ciertos procesos, comportamientos y toma de decisiones. A razón de ello, en el presente artículo se analiza la forma como se transmite la información referente al litigio, hacia la sociedad costarricense. Pues, “(...) la comunicación pública determina las estrategias y orientación de la atención pública, la agenda de temas predominantes que reclaman dicha atención y su discusión pública posterior" (Delgado, s.f., p. 11).

Es preciso mencionar que la importancia de este trabajo radica en que no se han encontrado referencias sobre documentos anteriores, en que se aplique la teoría del Neorrealismo para las relaciones políticas entre Costa Rica y Nicaragua a través del desarrollo de análisis de contenido aplicado a la prensa costarricense.

\section{Consideraciones metodológicas}

La metodología por seguir se basa en la observación de frases y palabras claves, que se clasificarán en categorías de análisis, construidas a partir de la teoría neorrealista para, posteriormente, analizar su contextualización, la idea que sostienen o la que se oponen, y su cuantificación. Para ello, se utilizarán cinco documentos digitales del diario costarricense "La Nación". En torno a ello, es importante destacar que el siguiente es un análisis cuantificado y analizado de forma manual, no se requirió del uso de software y tecnologías de análisis de contenido, los cuales pueden procesar mayores cantidades de datos e información, por lo que el presente documento representa una muestra micro, de la forma en que se puede realizar un análisis de contenido.

La razón de gestionar el presente trabajo de forma manual es porque se pretende ofrecer una hoja de ruta para estudiantes y personas interesadas que deseen

3 Término que hace referencia a la capacidad que tienen ciertos actores formales e informales para guiar y sancionar los comportamientos de un colectivo (Nye y Donahue, 2000). 
incursionar en el desarrollo de análisis de contenido y, para ello, requieren contar con referentes base. Por otra parte, porque representa -según el criterio de la autora- una herramienta de gran enriquecimiento académico y profesional para el desarrollo de investigaciones en cualquier área de las Ciencias Sociales y, efectivamente, el trabajo manual profundiza la experiencia: proceso-autor.

\section{Referente teórico}

El enfoque teórico que se utilizará para el análisis de contenido de prensa es la teoría neorrealista, expuesta por Kenneth Waltz, en su libro Teoría de la Política Internacional, (citado por Sodupe, 2003), la cual representa un mainstream de las Relaciones Internacionales; esta es una corriente que se deriva y tiene gran similitud con la clásica teoría realista, cuyo postulado principal es que las relaciones entre los Estados se basan en el principio de conflictividad. La teoría neorrealista surge del realismo y aparece como una teoría sistémica.

Sus principales postulados son los siguientes:

1. El Estado es el actor central, y los demás actores (no estatales) en el Sistema Internacional estarán subordinados a este.

2. La naturaleza de la vida política internacional es esencialmente conflictiva y estará siempre a "la sombra de la guerra", pues en el Sistema Internacional prima el principio de anarquía ${ }^{4}$ (Walks citado por Sodupe, 2003).

3. La motivación primordial humana viene dada por el poder y la seguridad. El poder es el medio para alcanzar la seguridad.

4. Y los Estados son actores racionales, autónomos y unitarios y son capaces de decidir y perseguir sus propios intereses (Walks citado por Sodupe, 2003).

Esta teoría expone, además, que cuanto más un Estado se comporte de forma racional y egoísta en el entorno internacional, más beneficios recibirá, pues el mismo sistema internacional se encargará de premiarlo. Siguiendo a Sodupe (2003), se manifiesta que la estructura internacional premiará a aquellos Estados que se acomoden a ella (actúen racionalmente) mediante la auto-recompensa. Esto representa una ventaja para alcanzar la supervivencia y seguridad y hará que se reduzcan las posibilidades de cooperación o las relaciones amistosas entre los

4 Término acuñado en Relaciones Internacionales para hacer referencia a la ausencia de un poder o gobierno central que dicte las normas a seguir por los Estados en el Sistema Internacional. 
Estados, pues cada país está pendiente de obtener ventajas por sí mismo y no de forma colectiva.

Los Estados apuestan por tener siempre beneficios relativamente mayores a los de los demás Estados y operan desde una lógica de ganancias relativas ${ }^{5}$, pues, si apuestan a tener relaciones de amistad y procesos de cooperación con otros países, el sistema funcionará desde la lógica de ganancias absolutas ${ }^{6}$. Estas ganancias absolutas pueden significar que otro Estado gane más -como en un proceso de integración regional donde si bien todos los países ganan, unos ganan más que otros. Esto representa una amenaza para el Estado, ya que todo país debe hacer lo posible porque ningún otro pase a ser más poderoso. Por ejemplo, mientras "para los neorrealistas es más importante la seguridad nacional, para los neoliberales lo es el bienestar económico" (Hormazábal \& Carreño, 2006, p.48).

Siguiendo a la profesora de Relaciones Internacionales de la Universidad de Barcelona, Mónica Salomón, se destaca que en el neorrealismo “(...) la cooperación internacional es más difícil de lograrse, más difícil de mantenerse y más dependiente de las relaciones de poder de los estados" (2002, p. 18). Asimismo, agrega:

(...) de ahí que teman que otros estados puedan obtener ganancias mayores que ellos en la cooperación (superarlos en ganancias relativas). Ese temor a que la cooperación con otros estados aumente su superioridad es lo que impediría la cooperación a largo plazo (2002, p. 18)

Es por ello que los Estados apuestan por su propia supervivencia y evitan los procesos de cooperación, lo cual les genera incertidumbre.

Según lo anterior, las relaciones entre los Estados son egoístas y conflictivas. Aquella nación que busque alcanzar sus propios objetivos se verá premiada por la estructura internacional, pues está trabajando por su propia seguridad y supervivencia; por esa razón, la cooperación se torna difícil en este escenario, aunque no es un proceso que se excluya. Sin embargo, cuando sucede, es

5 Término utilizado en la teoría neorrealista de las relaciones internacionales para hacer referencia a las ganancias individuales de un Estado con respecto a otro, en el Sistema Internacional. El Neorrealismo propone que cuantas más ganancias relativas posea un Estado mayor será su seguridad y poder en el SI.

6 Término utilizado en la teoría neorrealista de las relaciones internacionales para hacer referencia a las ganancias colectivas entre Estados, que resultan de procesos de integración, cooperación o alianza. El Neorrealismo ve en las ganancias absolutas una amenaza hacia el poder y la seguridad individual de los Estados. 
producto de que un Estado quiere maximizar sus ventajas, pero no porque desee el bienestar de otros países.

Ahora bien, de acuerdo con lo anterior y pasando de la teoría hacia la práctica, este trabajo pretende desarrollar un análisis de contenido y utilizar categorías de observación, fundamentadas en la teoría descrita. Dichas categorías se detallan a continuación:

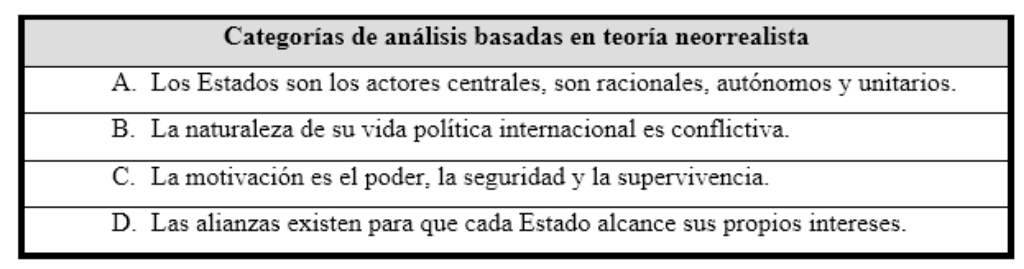

El análisis final giró en torno de lo siguiente: ¿actúa Nicaragua como Estado racional y egoísta para asegurar su supervivencia en el Sistema, según los documentos analizados? Para determinarlo, se utilizaron las anteriores categorías de observación y, posteriormente, se aplicó una metodología de conteo y análisis de palabras claves, frases explícitas e implícitas, así como actores relevantes que se clasificaron en cada categoría, según la idea que sostenían. Finalmente, se hizo un conteo del número de variables por categoría, para determinar en cuánto se validaban porcentualmente y, por ende, si la teoría propuesta se legitimaba. A continuación se explica lo que se hizo en la primera parte del análisis:

\begin{tabular}{|l|l|}
\hline \multicolumn{1}{|c|}{ Parte I } \\
\hline 1) & Actores voceros del conflicto y número de veces que aparecen. \\
\hline 2) & $\begin{array}{l}\text { Frecuencia con que aparecen las palabras claves, y su clasificación en cada categoría; } \\
\text { sumatoria de las palabras que forman parte de cada categoría, para determinar cuál } \\
\text { categoría se legitima más dentro del texto, de acuerdo con el número de palabras que la } \\
\text { sostienen. }\end{array}$ \\
\hline 3) & $\begin{array}{l}\text { Funciones de los actores dentro del texto: si es emisor o receptor de una acción. ¿Cuál es } \\
\text { la acción? ¿Cuál es el objetivo de la acción? Identificación de intenciones implícitas en el } \\
\text { texto. }\end{array}$ \\
\hline 4) & $\begin{array}{l}\text { Identificación de contextos temáticos utilizados por los conceptos equivalentes } \\
\text { (pertenecientes a una misma categoría). }\end{array}$ \\
\hline 5) Identificación de frases que contienen elementos implícitos y que sostienen alguna \\
categoría del neorrealismo.
\end{tabular}

En la segunda parte se llevó a cabo un análisis generalizado con el total de documentos, de la siguiente manera: 


\begin{tabular}{|c|}
\hline Parte II \\
\hline $\begin{array}{l}\text { 1. La frecuencia con que aparece cada actor en el total de documentos y la presentación } \\
\text { gráfica en términos porcentuales. }\end{array}$ \\
\hline $\begin{array}{l}\text { 2. Identificación de intenciones más frecuentes de los actores, en las ocasiones donde estos se } \\
\text { referían al conflicto, en la totalidad de documentos. Se dividieron en las intenciones de } \\
\text { actores costarricenses y nicaragüenses. Posteriormente, se grafican los resultados } \\
\text { porcentualmente. }\end{array}$ \\
\hline $\begin{array}{l}\text { 3. Identificación de la frecuencia con la que cada una de las categorías del neorrealismo se } \\
\text { legitiman dentro del universo de documentos, de acuerdo con la totalidad de palabras que la } \\
\text { sostienen. Se grafica porcentualmente. }\end{array}$ \\
\hline $\begin{array}{l}\text { 4. Frecuencia con que las categorías se legitiman, de acuerdo con las frases implícitas que la } \\
\text { sostienen en el universo de documentos. }\end{array}$ \\
\hline $\begin{array}{l}\text { 5. Frecuencia de contextos temáticos, de acuerdo con el conjunto de conceptos equivalentes } \\
\text { identificados. }\end{array}$ \\
\hline 6. Temas explícitos sobre intenciones de Nicaragua de crear conflictos. \\
\hline 7. \\
\hline
\end{tabular}

\section{Presentación de resultados}

Para empezar, es importante mencionar que aunque se eligieron noticias referentes al litigio territorial entre Costa Rica y Nicaragua, los documentos analizados podían legitimar o no la teoría neorrealista aquí utilizada pues, por ejemplo, se podía hacer alusión al conflicto existente desde una óptica cooperativa o de gestión, por vía diplomática, o mediante poder blando ${ }^{7}$ o de resolución alternativa de conflictos $(R A C)^{8}$, lo que no validaba la teoría explicada en el apartado anterior. No obstante, la teoría sí se hizo presente y se legitimó en los documentos analizados, como se evidenciará más adelante.

Adicionalmente, resulta fundamental saber que la selección de los documentos fue aleatoria, aunque se hizo tomando en cuenta que fueran documentos donde se expusiera información referente al conflicto. De acuerdo con las categorías de análisis, se logró identificar que en la totalidad de documentos se hicieron presentes las cuatro categorías del enfoque neorrealista, tal y como se verá a continuación:

La categoría más frecuente fue la B: la naturaleza de la vida política internacional del Estado es conflictiva, con un 51\% de frecuencia en los documentos. Seguida de la A: los Estados son los actores centrales, son racionales, autónomos y unitarios,

7 Término acuñado por Joseph Nye y utilizado en las relaciones internacionales para hacer referencia a la capacidad de un Estado para persuadir las acciones e intereses de otros, a través de vías diplomáticas, culturales e ideológicas. Es una forma alterna al poder duro.

8 La resolución alternativa de conflictos (RAC) es entendida como una forma de resolver conflictos al margen de los medios convencionales (Stone \& Rubenstein, 2000, p. 3). Incluye prácticas de consenso, negociación, mediación, arbitraje y buenos oficios, en general. 
con un 29\%. Posteriormente, la C: la motivación es el poder, la seguridad y la supervivencia, con un $16 \%$ y, finalmente, la D: las alianzas existen para que cada Estado alcance sus propios intereses, con un $4 \%$.

Existe una tendencia en los documentos analizados a convalidar la idea de que la naturaleza política del Estado es conflictiva, así como que los Estados son racionales, soberanos, y capaces de perseguir sus propios objetivos. Ante ello ¿cómo se percibe el vecino nicaragüense según el análisis desarrollado? Efectivamente, en concordancia con la pregunta anterior, se evidencia cómo a lo largo de todos los documentos se presenta una imagen conflictiva de Nicaragua en un $51 \%$ de las veces. Con lo anterior, es posible concluir que dentro del imaginario social costarricense se puede desencadenar un aumento de las tensiones y de la negativa existente -si se sigue presentando a Nicaragua solo como un vecino conflictivoteniendo en cuenta el nivel de incidencia que tienen los medios de comunicación en la formulación de opinión pública y en la guía de comportamientos sociales e imaginarios colectivos.

Cabe preguntarse si se percibe a Nicaragua desde el punto de vista político como un actor conflictivo, ¿será esta la razón por la que los medios de negociación por vía diplomática parecen haberse agotado? ¿Es esta la razón de acudir directamente a la Corte Internacional de Justicia? ¿Es lo que exponen medios de comunicación costarricenses una muestra de que esta sociedad percibe a Nicaragua como un país que genera constante desconfianza política y, por ello, estrategias de resolución alternativa de conflictos no parecen ser opciones para poner fin a las diferencias existentes entre ambos países?

Hasta el momento, este trabajo expone cómo los documentos de prensa costarricense aquí analizados muestran a Nicaragua como un país políticamente conflictivo. Sin embargo, parece ser que en el litigio territorial entre Costa Rica y Nicaragua, pese a ser histórico, no existe evidencia de que haya sido estudiado a profundidad. Un análisis recóndito sobre la comunicación política entre ambos actores, estudios sociológicos, culturales y de relaciones exteriores, significarían insumos importantes que aportar a la materia y a los gobiernos costarricenses. Con ello, se lograría tomar decisiones basadas en estrategias construidas sobre bases firmes y coherentes; por ejemplo, se puede ahondar en cuestiones sobre el nivel de incidencia de las inmigraciones nicaragüenses $-\mathrm{y}$ todas sus implicacionessobre la percepción política que tienen los costarricenses sobre Nicaragua y lo que ello puede significar en el desarrollo de negociaciones políticas, ciudadanas, comerciales y sociales. 
Por otra parte, al analizar la presencia e influencia de actores políticos involucrados en el conflicto, se observa diferentes porcentajes de presencia ${ }^{9}$ de algunas figuras en los documentos:

- La CIJ, con un 30\%.

- El canciller, Enrique Castillo, con un 20\%.

- Daniel Ortega, con un 16\%.

- Laura Chinchilla, con 12\%.

- Carlos Argüello, representante de Nicaragua ante la CIJ, con un 8\%.

- Ban Ki-Moon, Secretario General de la ONU, con un 6\%.

- Los presidentes de Colombia, Juan Manuel Santos, el de Panamá, Ricardo Martinelli, y Moisés Hallenlevens (Secretario de Relaciones Internacionales de Nicaragua) con un $2 \%$.

Es evidente que existe una mayor presencia de actores nicaragüenses que emiten criterio en el conflicto. Por su parte, de actores costarricenses solo se mencionan a la Presidenta de la República y al Canciller. En este punto, resulta interesante destacar que mientras se presenta a Daniel Ortega como el principal vocero de Nicaragua, en Costa Rica se resalta la figura del canciller Enrique Castillo, mientras la figura de la mandataria Chinchilla se minimiza.

En cuanto a la funcionalidad que tienen estos actores entre los documentos, se determinó cuáles eran las intenciones de los costarricenses y nicaragüenses cuando eran mencionados dentro del conflicto y se logró identificar que se menciona a Laura Chinchilla un $60 \%$ de las veces para ser señalada por la mala gestión que ha desempeñado sobre el conflicto y otras temáticas de gobernabilidad nacional. Por su parte, en la totalidad de las veces en que ella sí emite criterio, su oposición con respecto al conflicto es que presentará las quejas ante un organismo internacional (ver anexos, parte A: 1.3, 2.3, 3.3, 4.3 ,5.3; parte B: 2.1 y 2.2).

En cuanto a Enrique Castillo, en un $60 \%$ de las veces no emite criterios al respecto entre los documentos, pero cuando lo hace (40\%), el 100\% de las ocasiones es para atacar a la posición nicaragüense, sin buscar consenso, negociación o alguna práctica de resolución alterna sobre el litigio. Siguiendo lo anterior y en términos generales, se manifestó que en un 50\% de las veces en que participó alguno de los dos actores costarricenses, se señaló negativamente a Nicaragua y el otro 50\% concluyó que se llevaría el caso a la Corte.

9 Anexos parte A: 1.1, 2.1, 3.1, 4.1 ,5.1; parte B: Anexo 1. 
Ante la información expuesta, se concluye que en los documentos analizados se percibe a Nicaragua como un país conflictivo dentro del litigio. Sin embargo, con respecto a la imagen que se percibe de Costa Rica en los documentos, se concluye lo siguiente: Si bien Costa Rica señala a Nicaragua de gestionar políticas expansionistas que atentan contra su soberanía -es decir, que Nicaragua actúa como actor racional y en busca de poder- un 50\% de las veces en que Costa Rica se refiere al conflicto no hace más que acusarlo. O sea, que en ningún momento está emitiendo ningún tipo de amenaza contra la soberanía territorial nicaragüense y cuando se refiere al conflicto y hace alusión a proteger su territorio, o bien al territorio que cree le pertenece, manifiesta que acudirá a la Corte Internacional de Justicia.

La hipótesis aquí planteada radica en que en los artículos analizados se expone a Nicaragua como país conflictivo, lo que calza en la construcción de Estado que plantea el neorrealismo. Sin embargo, cuando se menciona a Costa Rica -si bien actúa como actor racional por querer proteger su soberanía territorial- en ningún momento actúa como uno que busca incrementar el conflicto, sino más bien apaciguarlo al llevarlo a un tribunal internacional.

Pese a que Costa Rica está abogando por resolver el litigio, solo menciona el hecho de acudir a la CIJ, pero no hace énfasis en querer gestionar alguna estrategia de negociación diplomática o de resolución alternativa de conflictos, por ejemplo, lo que parece contrario a las tradiciones pacifistas y de buenas prácticas diplomáticas por las que se caracteriza. En síntesis, se legitima la teoría neorrealista en la forma como se percibe a Nicaragua, pero no en la forma como se habla de Costa Rica, aunque este no haya hecho esfuerzos importantes por resolver el problema desde su músculo diplomático.

En concordancia con lo planteado, es posible determinar que de la totalidad de ocasiones en que los actores nicaragüenses se refirieron al litigio, el $75 \%$ de las veces no mencionaron la negociación y atacaron de forma negativa a Costa Rica, como país que posee territorio que les corresponde y debe ser recuperado. Solo en un $25 \%$ de ocasiones se refirieron a acudir a algún organismo o tribunal internacional, lo que nuevamente fortalece un enfoque teórico neorrealista, sobre la constante naturaleza en conflicto en un $75 \%$.

Por su parte, en relación con el análisis de frases implícitas detectadas en los documentos, es posible observar lo siguiente: se legitima en un 50\% la categoría que expone que los Estados son autónomos, racionales y unitarios, en referencia a Nicaragua. Es evidente que sí se respeta y reconoce la soberanía territorial de ese 
país. En un 31\% de las frases implícitas, se hace referencia a que la motivación del actuar de Nicaragua es el poder, la seguridad y su supervivencia en el sistema internacional. Con ello, nuevamente se refuerzan la teoría propuesta y los escenarios desarrollados con anterioridad (ver anexos, parte A: 1.5, 2.5, 3.5, 4.5, 5.5 y parte B: 4$)$.

En las ocasiones en que los documentos hacen alusión a Nicaragua en el conflicto, se observa que el $50 \%$ de las veces se dijo que Nicaragua cuenta con plan expansionista, que incluye el reclamo de Guanacaste y el apoderamiento de territorios de ultramar, motivados por el crecimiento económico y territorial, lo que nuevamente legitima la noción de que Costa Rica percibe a Nicaragua como un Estado construido desde la teoría neorrealista y que responde a dinámicas de enemistad, en áreas como las de las relaciones políticas.

Asimismo, un $17 \%$ de las veces se señala a Ortega de manera explícita como conflictivo; también en otro $17 \%$ de las ocasiones se indica que Ortega representa un desequilibrio para la región. Aunado a ello, se indica que Nicaragua desvirtúa la imagen de Gobierno costarricense. Finalmente, se evidencia que cuando El Diario se refiere a los intereses expansionistas de Nicaragua, señala que las motivaciones principales son en un $67 \%$ sed de crecimiento territorial y en un $33 \%$ de crecimiento económico.

Estos datos manifiestan de nuevo cómo se expone, tanto implícita como explícitamente, la naturaleza conflictiva entre los Estados y cómo estos actúan racionalmente de acuerdo con planes y estrategias que incluyen intereses políticos, militares, y económicos, que buscan la supervivencia y seguridad de La Nación en el Sistema Internacional. En este caso, según la retórica utilizada en la prensa costarricense, los intereses de Nicaragua se enfocan en aumentar su crecimiento económico, militar y territorial, aunque ello implique establecer relaciones de conflicto con otros Estados.

Finalmente, es esencial destacar que se da un gran reconocimiento de la competencia que tiene la Corte Internacional de Justicia en el conflicto, pues se validó su labor el $100 \%$ de las veces que fue mencionada en el documento. En este caso, se presenta una ambigüedad con respecto a la teoría, ya que pese a que existe un conflicto de por medio en el que se destacan deseos expansionistas, de poder político, territorial y económico por parte de Nicaragua, tanto Costa Rica como Nicaragua reconocen la labor de la CIJ como tribunal que soluciona controversias. Con esto es posible concluir que si bien la teoría explica la imagen que exponen los medios costarricenses sobre Nicaragua, como actor 
conflictivo, en busca de poder y supervivencia, no explica el desenlace del conflicto en totalidad.

\section{Conclusiones}

Es posible observar cómo el tema del conflicto entre Costa Rica y Nicaragua encuentra un cierto sostén en la manera conflictiva como la prensa expone la información. Esto a la vez refuerza el enfoque teórico aquí utilizado para analizar los datos: el neorrealismo. Se evidencia, de manera contundente, cómo los artículos analizados sí exponen a Nicaragua como un país conflictivo en esencia. Aunado a ello, en ninguna de las partes de los documentos se habla, implícita o explícitamente, de manera positiva sobre el otro país.

Primero, se manifiesta como hay un deterioro en las relaciones bilaterales de ambos países, que parece estar vinculado a la carencia de estrategias por parte de las cancillerías y producto de relaciones diplomáticas con comunicación poco asertiva. Esto se manifiesta de manera cuantificable, cuando el análisis expone que no se presentó ningún dato entre los documentos donde alguno de los dos países buscara el diálogo y la negociación de manera directa con su contraparte, sino que, al contrario, las únicas opciones fueron llevar la denuncia a un organismo internacional y señalar a la contraposición, sin posibilidad de abrir consenso, o alguna otra práctica alternativa en su defecto.

Ante esta contundente tendencia de no utilizar las vías diplomáticas o cooperativas para dar fin al conflicto, es válido preguntarse: ¿cuál es la razón de no utilizar la vía diplomática o estrategias de RAC? ¿Tiene esto incidencia en los procesos de integración regional, llámese SICA o CELAC? ¿Tiene esto efectos negativos sobre las agendas binaciones entre ambas naciones o entre sus relaciones comerciales, si se toma en cuenta que Nicaragua es de los socios comerciales más importantes para Costa Rica?

En resumidas cuentas ¿qué incidencia tiene mantener el litigio activo y que la prensa costarricense exponga a Nicaragua como enemigo conflictivo para las dinámicas de cooperación regional? En este punto es preciso aclarar cómo la lógica de cooperación internacional responde a otras tendencias teóricas como neoliberalismo y constructivismo, y no al neorrealismo, el cual expone que las alianzas existen en función de que los Estados buscan alcanzar sus propios intereses y no porque deseen la cooperación per se, ni el bienestar de otros países, pues todo gira en torno a la auto-ayuda, por lo que resulta interesante analizar 
este conflicto dentro de los actuales procesos de cooperación en que ambos países están involucrados.

Primero, es posible percibir cómo ambos países actúan como Estados soberanos, autónomos y unitarios al defender sus respectivos territorios, su jurisdicción, sus fronteras y sus espacios marítimos. Sin embargo, se evidencia cómo Nicaragua actúa como Estado racional con una ventaja considerable sobre Costa Rica, pues ha tomado más medidas para imponer su autoridad: cuenta con presencia de fuerzas armadas, y hace uso de estas para proteger su línea fronteriza. Segundo, amenaza a Costa Rica con recuperar la provincia guanacasteca y mantiene un constante clima de advertencia en sus discursos. Tercero, cuenta con una reciente legitimidad en materia de soberanía territorial, pues, para el 2012 le ganó territorios de ultramar, y, además, recientemente empieza políticas de negociación para su explotación económica, sin importar si estos le pertenecen o no, lo que crea cierta imagen de "intimidación" para Costa Rica.

En términos de capacidades, el gobierno nicaragüense parece estar adquiriendo mayor poder que Costa Rica; juega con piezas claves como Daniel Ortega, no solo Presidente de Nicaragua, sino importante líder de los países de tendencia bolivariana, a diferencia de figuras como la mandataria Chinchilla, que en los mismos datos de los artículos ya expuestos no parece tener mayor presencia y relevancia en el conflicto. Por su parte, Costa Rica actúa, en menor frecuencia, como un Estado racional, al detectar la carencia de un plan o estrategia de gobierno claro y establecido para hacerle frente a las diferencias limítrofes. Mientras que Nicaragua, parece tener un norte definido hacia el cual quiere ir; norte que los medios nacionales catalogan como objetivos expansionistas.

Efectivamente, se puede concluir que desde la cobertura de información costarricense (en el diario La Nación) es posible apreciar a Nicaragua como un actor fuerte y racional, que responde a la lógica neorrealista propuesta por $\mathrm{K}$. Waltz (dada la manera conflictiva y racional con la que actúa), mientras que Costa Rica se muestra un poco más débil a la hora de luchar por asegurarse un buen sitio en el Sistema Internacional, siendo evidente en la poca incidencia que tienen, por ejemplo, la presidenta Laura Chinchilla Miranda y el Canciller Enrique Castillo en el conflicto. Costa Rica no parece poseer una estrategia en concordancia con líneas de poder blando, poder duro o poder inteligente sobre el caso Nicaragua.

Por último, la presencia de la CIJ como actor fundamental dentro del conflicto, valida por una parte la teoría neorrealista, pues reconoce la existencia de un conflicto, pero por otro lado manifiesta ambigüedad, dado que la Corte como 
Tribunal Internacional representa un organismo que resuelve litigios, es decir, en algún momento existe la posibilidad de ponerles fin; ante ello, se puede interpretar que la naturaleza conflictiva no es necesariamente constante entre los Estados, o bien, la teoría no aplica en su totalidad para este caso de análisis.

Como reflexión final, es importante reconocer el análisis de la comunicación política y de medios de comunicación nacional e internacional, con el fin de medir la forma como se genera opinión pública, así como prospectar escenarios sobre las acciones y los intereses de otros gobiernos, lo que permitirá tener insumos para generar estrategias, impulsar posiciones políticas e, incluso, generar política pública de manera racional.

\section{Recomendaciones}

1. Generar diálogos y coordinación entre gobierno-academia costarricense, para establecer una estrategia clara y en el largo plazo con el objetivo de hacer frente al histórico litigio fronterizo Costa Rica-Nicaragua, el cual se caracteriza por tener momentos de crisis que alteran el status quo de las relaciones bilaterales entre ambos países. Se debe tener la capacidad de enfrentar esas crisis de manera asertiva y estratégica. Además, debe existir un profundo auto-conocimiento de lo que se desea alcanzar por medio de acciones específicas de política exterior.

2. Fortalecer el músculo diplomático costarricense con las relaciones con Nicaragua, con el fin de generar comunicación asertiva, mesas de diálogo y negociación, que agoten todas las formas alternativas de solución conflictos antes de acudir a un tribunal como la Corte Internacional de Justicia.

3. El gobierno costarricense, específicamente la Cancillería de la República, debe generar análisis de comunicación política, que le permita utilizar instrumentos como el análisis de discurso, de contenido y de coyuntura, con el fin de conocer los intereses e intenciones de otros actores internacionales como Nicaragua y la forma cómo se difunde la información en medios de comunicación local e internacional. Lo anterior permitirá una toma de decisiones y posturas políticas más coherentes, estudiadas y fundamentadas. Algunas acciones que podrían realizarse son las siguientes:

- Monitorear, estudiar y analizar las acciones del vecino país nicaragüense, a través del seguimiento de los discursos de los líderes políticos y militares, 
así como dar seguimiento a la información emitida por los medios de comunicación nicaragüense.

- Utilizar tecnologías y software de análisis de contenido y discurso, con el fin de procesar mayores cantidades de información y, con ello, tener una mejor cobertura sobre esta, lo cual generará insumos importantes para el desarrollo de análisis de coyunturas específicas. Se puede analizar no solo lo que emiten los medios de comunicación, sino comunicados oficiales de gobierno, lo que hace más enriquecedor y completo el análisis.

- Realizar un análisis de comunicación política y social acerca de cómo se percibe el conflicto fronterizo para la sociedad y el círculo político, nicaragüense y costarricense, con el fin de generar un estudio comparativo sobre el imaginario de cada país. Esto permitirá acabar con posibles supuestos sobre las intenciones de Nicaragua en el conflicto; además, creará insumos necesarios para entender su lógica con mayor profundidad, por lo que la generación de estrategias diplomáticas y de política exterior de Costa Rica hacia Nicaragua tendrá una base sobre la cual sostenerse.

4. Reflexionar acerca de las consecuencias políticas nacionales y regionales, de mantener relaciones de conflictividad territorial con Nicaragua -como se evidenció en este artículo desde la lógica neorrealista-en relación con procesos de cooperación y alianza regional -como SICA, CELAC- en los que están involucrados ambos países, y que parecen ser de interés nacional para los dos.

5. Gestionar análisis integrales que involucren variables políticas, económicas, culturales y sociales, que permitan entender las diferencias constantes y actuales entre ambos países desde una perspectiva macro. Por ejemplo, cabe preguntarse ¿cuál ha sido la incidencia de flujos migratorios Nicaragua-Costa Rica, en la percepción política que existe entre ambos Estados?

\section{Referencias}

Delgado, H. (s.f). La aportación de la opinión pública y la comunicación social a la Ciencia Política. Universidad de Barcelona. Recuperado de: http:// www.academia.edu/8211606/La_opini\%C3\%B3n_p\%C3\%BAblica_y_la_ comunicaci\%C3\%B3n_social_a_la_Ciencia_pol\%C3\%Adtica

Hormazábal, R. \& Carreño, E. (2006). Introducción a las teorías de las Relaciones Internacionales. Universidad de Chile. Recuperado de: http://mazinger.sisib.uchile. cl/repositorio/ap/instituto_de_asuntos_publicos/h200710261441dad14.diciembre.pdf 
Mata, E. (11 de septiembre del 2013). Costa Rica alertará en la ONU sobre expansionismo de Nicaragua. La Nación. Recuperado de: http://www.nacion.com/nacional/ politica/Costa-Rica-expansionismo-Nicaragua-ONU_0_1365463493.html

Nye, J \& Donahue, J. (2000). Governance in a globalizing world. The Brookings Institution Press. Washington D.C.

Salomón, M. (2002). La teoría de las relaciones internacionales en los albores del siglo XXI: diálogo, disidencias, aproximaciones. Revista CIDOB d'Afers Internacionals. Recuperado de http://www.raco.cat/index.php/revistacidob/ article/viewFile/28242/28076

Sequeira, A. (25 de julio del 2013). País Busca Frenar interés petrolero en Nicaragua. La Nación. Recuperado de: http:/www.nacion.com/nacional/politica/Costa-Ricaopciones-explotacion-petrolera_0_1355864458.html

Sodupe, K. (2003). La teoría de las relaciones internacionales a comienzos del siglo XXI. País Vasco, Universidad del País Vasco.

Stone, M. \& Ruberstein, W. (2000). Principios de la Resolución Alternativa de Conflictos: resumidos, reexpuestos y comentados. Universidad de Florida. Recuperado de: https://www.law.ufl.edu/_pdf/academics/centers-clinics/clinics/conservation/ resources/ADR_spanish.pdf

Sun, Tzu. (s.f). El arte de la guerra. Recuperado de: http://mediacion.ic acor.es / descarga/Libros/EL_ARTE_DE_LA_GUERRA.pdf 


\section{Anexos}

Parte 1: Tablas por documento

Documento 1: "País busca frenar interés petrolero de Nicaragua" 1

Tabla 1.1

Frecuencia con que aparecen los actores

\begin{tabular}{lc}
\hline \multicolumn{1}{c}{ Actor } & Frecuencia simple observada \\
\hline Laura Chinchilla & 1 \\
Enrique Castillo & 5 \\
Daniel Ortega & 4 \\
Moisés Hallenlevens (Vicepresidente Nicara- & 1 \\
gua) & 2 \\
Corte Internacional de Justicia & \\
\hline
\end{tabular}

Fuente: Elaboración propia con datos tomados de Sequeira (2013).

1 Sequeira, A. (25 de julio del 2013). País busca frenar interés petrolero en Nicaragua. La Nación. Recuperado de: http://www.nacion.com/nacional/politica/Costa-Rica-opciones-explotacionpetrolera_0_1355864458.html 


\section{Tabla 1.2}

Frecuencia con que aparecen palabras claves y frecuencia con que se legitiman las categorías del neorrealismo de acuerdo con la idea que sostiene cada palabra.

\begin{tabular}{|c|c|c|c|c|c|c|}
\hline Variable & Código & $\begin{array}{l}\text { Frecuencia } \\
\text { observada }\end{array}$ & & Cat & rías & \\
\hline & & & A & B & $\mathrm{C}$ & $\mathrm{D}$ \\
\hline Expansionista & Expan & 2 & & & I-I & \\
\hline Explotación petrolera & Petro & 2 & & & $\mathrm{I}-\mathrm{I}$ & \\
\hline Plan & Plan & 2 & I-I & & & \\
\hline Protesta & Prot & 2 & & I-I & & \\
\hline Cancillería & Canci & 1 & & & & I \\
\hline Reclamo & Recla & 1 & & I & & \\
\hline Límites & Lim & 3 & I-I-I & & & \\
\hline Marítimo & Mart & 1 & I & & & \\
\hline Conflictos & Confli & 1 & & I & & \\
\hline Invasión & Invas & 1 & & I & & \\
\hline Derechos & Dere & 1 & I & & & \\
\hline Frontera & Front & 1 & I & & & \\
\hline Territorio & Terri & 1 & I & & & \\
\hline Total & & 19 & 9 & 5 & 4 & 1 \\
\hline
\end{tabular}

Fuente: Elaboración propia con datos tomados de Sequeira (2013).

\section{Categorías}
A. Los Estados son los actores centrales, son racionales, autónomos y unitarios.
B. La naturaleza de su vida política internacional es conflictiva.
C. La motivación es el poder, la seguridad y la supervivencia.
D. Las alianzas existen para que cada Estado alcance sus propios intereses.

Las categorías que más se legitiman por mayoría de las palabras claves, son la A y la B. 


\section{Tabla 1.3}

\section{Intenciones de los actores}

\begin{tabular}{|c|c|c|c|}
\hline $\begin{array}{l}\text { Actor o receptor } \\
\text { de acción }\end{array}$ & Acción & Objeto de la acción & Síntesis \\
\hline $\begin{array}{l}\text { Laura Chin- } \\
\text { chilla }\end{array}$ & $\begin{array}{l}\text { Señalada de mal } \\
\text { asesoramiento por } \\
\text { parte de Hellenle- } \\
\text { vens. }\end{array}$ & $\begin{array}{l}\text { El medio costa- } \\
\text { rricense expone } \\
\text { cómo Nicaragua } \\
\text { subestima labores } \\
\text { de Chinchilla. }\end{array}$ & $\begin{array}{l}\text { Nicaragua busca } \\
\text { desvirtuar imagen de la } \\
\text { mandataria. }\end{array}$ \\
\hline Enrique Castillo & $\begin{array}{l}\text { Acusa a Nicaragua } \\
\text { de plan expansio- } \\
\text { nista. }\end{array}$ & $\begin{array}{l}\text { Indicar malas inten- } \\
\text { ciones del gobierno } \\
\text { nicaragüense. }\end{array}$ & $\begin{array}{l}\text { Legitimar la posición } \\
\text { costarricense, señalando } \\
\text { las intenciones conflicti- } \\
\text { vas de Nicaragua. }\end{array}$ \\
\hline Daniel Ortega & $\begin{array}{l}\text { Señalado de llevar } \\
\text { dos conflictos a } \\
\text { la CIJ: invasión } \\
\text { Calero y cons- } \\
\text { trucción ruta } 1856 \text {. } \\
\text { Señalado por } \\
\text { control de medios } \\
\text { nicaragüenses. }\end{array}$ & $\begin{array}{l}\text { Señalado de poseer } \\
\text { naturaleza conflic- } \\
\text { tiva.Señalado de } \\
\text { tener control sobre } \\
\text { la información del } \\
\text { conflicto. }\end{array}$ & $\begin{array}{l}\text { Presentar una imagen } \\
\text { negativa y conflictiva } \\
\text { de Ortega ante la } \\
\text { opinión pública. } \\
\text { Exponer la posible } \\
\text { desinformación por } \\
\text { parte de los medios y } \\
\text { gobierno nicaragüense. }\end{array}$ \\
\hline $\begin{array}{l}\text { Moisés Hallen- } \\
\text { levens }\end{array}$ & $\begin{array}{l}\text { Señala mal } \\
\text { asesoramiento de } \\
\text { Chinchilla. }\end{array}$ & $\begin{array}{l}\text { Indicar incompe- } \\
\text { tencia de Chinchilla } \\
\text { en los tópicos del } \\
\text { conflicto y subesti- } \\
\text { mar su gobierno. }\end{array}$ & $\begin{array}{l}\text { Nicaragua busca } \\
\text { justificar sus acciones, } \\
\text { a la vez que deslegitima } \\
\text { acciones costarricenses. }\end{array}$ \\
\hline CIJ & $\begin{array}{l}\text { Receptor de las } \\
\text { protestas del } \\
\text { conflicto. }\end{array}$ & $\begin{array}{l}\text { Exponer la imagen } \\
\text { de la Corte, como } \\
\text { mecanismo compe- } \\
\text { tente en el conflicto. }\end{array}$ & $\begin{array}{l}\text { CIJ como alternativa } \\
\text { para dar cese al litigio. }\end{array}$ \\
\hline
\end{tabular}

Fuente: Elaboración propia con datos tomados de Sequeira (2013). 


\section{Tabla 1.4}

Grupos de conceptos equivalentes por categoría y la idea que sostienen en conjunto

\begin{tabular}{|c|c|c|}
\hline Categoría & $\begin{array}{l}\text { Grupos de conceptos } \\
\text { equivalentes }\end{array}$ & Contextos temáticos donde son utilizados \\
\hline A & Plan-Lim-Dere-Front-Terri & $\begin{array}{l}\text { Se señala la violación al derecho, territorio, } \\
\text { fronteras y límites de Costa Rica, producto } \\
\text { de un plan estructurado de Nicaragua. }\end{array}$ \\
\hline $\mathrm{B}$ & Recla-Prot-Confli-Inva & $\begin{array}{l}\text { Costa Rica protesta y reclama los territo- } \\
\text { rios invadidos por Nicaragua como suyos, } \\
\text { en un contexto de conflictividad. }\end{array}$ \\
\hline $\mathrm{C}$ & Expan-Petro & $\begin{array}{l}\text { Costa Rica señala las intenciones de } \\
\text { Nicaragua, de expansionistas y uno de sus } \\
\text { intereses es la explotación petrolera en } \\
\text { territorios ajenos. }\end{array}$ \\
\hline $\mathrm{D}$ & Canci-Marit & $\begin{array}{l}\text { La Cancillería costarricense responde al } \\
\text { conflicto y busca resolver la disputa en } \\
\text { torno a los intereses marítimos. }\end{array}$ \\
\hline
\end{tabular}

Tabla 1.5

Frases que sostienen una idea implícita que legitima las categorías.

\begin{tabular}{|c|c|c|}
\hline Frases & Variables & Categoría \\
\hline $\begin{array}{l}\text { "Oferta está contenida en el documento Petroleum } \\
\text { Promotional Folder of Nicaragua, del Ministerio de } \\
\text { Energía y Minas de la administración Ortega e incluye } \\
18 \text { bloques en el océano Pacífico y } 55 \text { en el mar } \\
\text { Caribe." }\end{array}$ & $\begin{array}{l}\text { Interés-de- } \\
\text { sarrollo } \\
\text { económico }\end{array}$ & $\begin{array}{l}\text { C: La motivación es } \\
\text { el poder, la seguridad } \\
\text { y la supervivencia. }\end{array}$ \\
\hline $\begin{array}{l}\text { "Oferta está contenida en el documento Petroleum } \\
\text { Promotional Folder of Nicaragua, del Ministerio } \\
\text { de Energía y Minas de la administración Ortega, e } \\
\text { incluye } 18 \text { bloques en el océano Pacífico y } 55 \text { en el mar } \\
\text { Caribe." }\end{array}$ & $\begin{array}{l}\text { Territorio-blo- } \\
\text { ques-sobe- } \\
\text { ranía }\end{array}$ & $\begin{array}{l}\text { A: Los Estados son } \\
\text { los actores centrales, } \\
\text { son racionales, autó- } \\
\text { nomos y unitarios. }\end{array}$ \\
\hline $\begin{array}{l}\text { "Los abogados nicaragüenses afirmaron que no se } \\
\text { reconocen derechos ticos ni en bahía de San Juan del } \\
\text { Norte (Caribe) ni en bahía Salinas (Pacífico)". }\end{array}$ & $\begin{array}{l}\text { Defensa-so- } \\
\text { beranía-dere- } \\
\text { cho-territorio. }\end{array}$ & $\begin{array}{l}\text { A: Los Estados son } \\
\text { los actores centrales, } \\
\text { son racionales, autó- } \\
\text { nomos y unitarios. }\end{array}$ \\
\hline
\end{tabular}

Fuente: Elaboración propia con datos tomados de Sequeira (2013). 
Documento 2: Daniel Ortega insiste en reclamar Guanacaste para Nicaragua ${ }^{2}$

Tabla 2.1

Frecuencia con que aparecen los actores

\begin{tabular}{lcc}
\hline & Actor & Frecuencia simple observada \\
\hline Daniel Ortega & 3 \\
CIJ & 4 \\
\hline
\end{tabular}

Fuente: Elaboración propia con datos de Lázcarez (2013).

\section{Tabla 2.2}

Frecuencia con que aparecen palabras claves y frecuencia con que se legitiman las categorias del neorrealismo de acuerdo con la idea que sostiene cada palabra.

\begin{tabular}{|c|c|c|c|c|c|c|}
\hline Variable & Código & $\begin{array}{c}\text { Frecuencia } \\
\text { observada }\end{array}$ & & Cat & orías & \\
\hline & & & A & B & $\mathrm{C}$ & $\mathrm{D}$ \\
\hline Límites marítimos & Limarítimo & 2 & I-I & & & \\
\hline Espacio marítimo: & Espamari & 2 & I-I & & & \\
\hline Disputan & Dispu & 1 & & I & & \\
\hline Reclamar & Recla & 1 & & I & & \\
\hline Fuerza Naval & Funava & 1 & & & I & \\
\hline Litigio & Lit & 1 & & I & & \\
\hline Invasión & Inva & 1 & & I & & \\
\hline Territorio & Terri & 3 & I-I-I & & & \\
\hline Daños & Dañ & 2 & & I-I & & \\
\hline Explotación petrolera: & Petro & 1 & & & I & \\
\hline Fronterizo & Front & 1 & I & & & \\
\hline Soberanía & sobe & 1 & I & & & \\
\hline Concesiones petroleras & Conpetro & 1 & & & I & \\
\hline Expansionismo & Expan. & 1 & & & I & \\
\hline Total & & 19 & 9 & 6 & 4 & 0 \\
\hline
\end{tabular}

Fuente: Elaboración propia con datos de Lázcarez (2013).

2 Lázcarez, C. (13 de agosto del 2013). Daniel Ortega insiste en reclamar Guanacaste. La Nación. Recuperado de: http://www.nacion.com/nacional/politica/Ortega-insiste-reclamarGuanacaste_0_1359864072.html 


\section{Categorías:}
A. Los Estados son los actores centrales, son racionales, autónomos y unitarios.
B. La naturaleza de su vida política internacional es conflictiva.
C. La motivación es el poder, la seguridad y la supervivencia.
D. Las alianzas existen para que cada Estado alcance sus propios intereses.

\section{Tabla 2.3}

Intenciones de los actores

\begin{tabular}{|c|c|c|c|}
\hline $\begin{array}{l}\text { Actor o } \\
\text { receptor de } \\
\text { acción }\end{array}$ & Acción & Objeto de la acción & Síntesis \\
\hline $\begin{array}{l}\text { Daniel } \\
\text { Ortega }\end{array}$ & $\begin{array}{l}\text { Disposición a dar } \\
\text { cese a los conflictos } \\
\text { territoriales con } \\
\text { CR, llevándolos a } \\
\text { la CIJ. Reclamar } \\
\text { Guanacaste en el } \\
\text { aniversario Fuerza } \\
\text { Naval. Negociación } \\
\text { territorios marítimos } \\
\text { para explotación } \\
\text { petrolera con otros } \\
\text { países. }\end{array}$ & $\begin{array}{l}\text { Legitimar sus accio- } \\
\text { nes en el conflicto, } \\
\text { desde la imagen de } \\
\text { diálogo y negocia- } \\
\text { ción. Imponer temor } \\
\text { a Costa Rica sobre } \\
\text { posible reclamo de su } \\
\text { territorio. }\end{array}$ & $\begin{array}{l}\text { Ante la amenaza de los } \\
\text { reclamos de CR por los } \\
\text { territorios de ultramar } \\
\text { que Nicaragua está ne- } \\
\text { gociando, Ortega expone } \\
\text { la necesidad de resolver } \\
\text { los conflictos ante la CIJ, } \\
\text { a la vez que reclama el } \\
\text { territorio guanacasteco } \\
\text { como estrategia para } \\
\text { intimidar al gobierno } \\
\text { costarricense. }\end{array}$ \\
\hline CIJ & $\begin{array}{l}\text { Se presenta como } \\
\text { organismo competen- } \\
\text { te en el conflicto. }\end{array}$ & $\begin{array}{l}\text { Llevar desarrollo } \\
\text { económico a su país, } \\
\text { a costas de explotar te- } \\
\text { rritorio costarricense. }\end{array}$ & $\begin{array}{l}\text { Ortega hace mención } \\
\text { de llevar litigio a la } \\
\text { corte, posterior de ganar } \\
\text { territorios, por fallo del } \\
\text { mismo organismo. }\end{array}$ \\
\hline
\end{tabular}

Fuente: Elaboración propia con datos de Lázcarez (2013). 
Tabla 2.4

Grupos de conceptos equivalentes por categoría y la idea que sostienen en conjunto.

\begin{tabular}{|c|c|c|}
\hline Categoría & $\begin{array}{l}\text { Grupo de conceptos } \\
\text { equivalentes }\end{array}$ & Contextos temáticos donde son utilizados \\
\hline A & $\begin{array}{l}\text { Limari-Esmari-Te- } \\
\text { rri-Fron-Sobe }\end{array}$ & $\begin{array}{l}\text { Costa Rica señala la violación de su } \\
\text { soberanía, sus límites y espacios maríti- } \\
\text { mos, así como de sus fronteras, por parte } \\
\text { de Nicaragua. }\end{array}$ \\
\hline $\mathrm{B}$ & Dispu-Recla-Lit-Inva-Dañ & $\begin{array}{l}\text { Señala la actual disputa con Nicaragua, } \\
\text { los reclamos de Guanacaste, así como la } \\
\text { invasión y los daños que causa el mismo } \\
\text { país en la línea fronteriza. }\end{array}$ \\
\hline $\mathrm{C}$ & $\begin{array}{l}\text { Funava-Petro-Conpet-Ex- } \\
\text { pan }\end{array}$ & $\begin{array}{l}\text { Se exponen los intereses de Nicaragua } \\
\text { de aumentar su poder y supervivencia, } \\
\text { mediante el fortalecimiento de Fuerza } \\
\text { Naval, los deseos de explotación petrolera } \\
\text { y su política expansionista. }\end{array}$ \\
\hline $\mathrm{D}$ & ------------------------------ & -------------------------------------- \\
\hline
\end{tabular}

Fuente: Elaboración propia con datos de Lázcarez (2013).

\section{Tabla 2.5}

Frases que sostienen una idea implícita que legitima las categorías

\begin{tabular}{llc}
\hline \multicolumn{1}{c}{ Frases } & \multicolumn{1}{c}{ Variable } & Categoría \\
\hline "Eso le permitiría a Nicaragua recuperar un & Interés & D \\
inmenso territorio, si la sentencia favoreciera & Territorio & A \\
a Nicaragua" (Ortega) & Desarrolloy crecimiento & C \\
& & \\
"Esa provincia fue cedida a Costa Rica & Interés & D \\
"cuando el país estaba enfrentando al & Territorio & A \\
expansionismo yanqui, entonces pienso que & Expansionismo & $\mathrm{C}$ \\
eventualmente también podemos recurrir a la & Desarrollo y crecimiento & $\mathrm{C}$ \\
Corte" (Ortega) & & \\
\hline
\end{tabular}

Fuente: Elaboración propia con datos de Lázcarez (2013). 


\section{Documento 3: "Costa Rica alertará a la ONU sobre expansionismo de Nicaragua" $"$}

\section{Tabla 3.1}

Frecuencia con que aparecen los actores

\begin{tabular}{lc}
\hline \multicolumn{1}{c}{ Actores } & Frecuencia simple observada \\
\hline Laura Chinchilla & 3 \\
Enrique Castillo & 3 \\
Daniel Ortega & 1 \\
Ban Ki-Moon (Secretario ONU) & 1 \\
Juan Manuel Santos (Presidente Colom- & 1 \\
bia) & 1 \\
Ricardo Martinelli (Presidente Panamá) & 1 \\
CIJ & \\
\hline
\end{tabular}

Fuente: Elaboración propia según datos de Mata (2013).

3 Mata, E. (11 de septiembre del 2013). Costa Rica expondrá en la ONU sobre expansionismo nicaragüense. La Nación. Recuperado de: http://www.nacion.com/nacional/politica/Costa-Ricaexpansionismo-Nicaragua-ONU_0_1365463493.html 


\section{Tabla 3.2}

Frecuencia con que aparecen palabras claves y frecuencia con que se legitiman las categorías del neorrealismo de acuerdo con la idea que sostiene cada palabra.

\begin{tabular}{llccccc}
\hline \multicolumn{1}{c}{ Variable } & Código & $\begin{array}{c}\text { Frecuencia } \\
\text { observada }\end{array}$ & \multicolumn{5}{c}{ Categorías } \\
\hline Expansionista & Expan & 2 & & & I-I & \\
\cline { 4 - 7 } Protesta & Prot & 2 & & I-I & & \\
Queja & Quej & 2 & & I-I & & \\
Intereses & Inte & 1 & & & & I \\
Reclamo & Recla & 1 & & I & & \\
Tensiones & Ten & 1 & & I & & \\
Armamento & Arma & 1 & & & I & \\
Ejército & Ejer & 1 & & & I & \\
Territorio & Terri & 1 & I & & & \\
Diplomacia & Diplo & 1 & & & & I \\
Litigio & Lit & 1 & & I & & \\
Invasión & Inva & 1 & & I & & \\
Total & & $\mathbf{1 5}$ & $\mathbf{1}$ & $\mathbf{8}$ & $\mathbf{4}$ & $\mathbf{2}$ \\
\hline
\end{tabular}

Fuente: Elaboración propia según datos de Mata (2013).

\section{Categorías:}
A. Los Estados son los actores centrales, son racionales, autónomos y unitarios.
B. La naturaleza de su vida política internacional es conflictiva.
C. La motivación es el poder, la seguridad y la supervivencia.
D. Las alianzas existen para que cada Estado alcance sus propios intereses. 


\section{Tabla 3.3}

Intenciones de los actores

\begin{tabular}{|c|c|c|c|}
\hline $\begin{array}{c}\text { Actores receptores } \\
\text { de acción }\end{array}$ & Acción & Objeto de la acción & Síntesis \\
\hline $\begin{array}{l}\text { Laura Chinchilla } \\
\text { (actor) }\end{array}$ & $\begin{array}{l}\text { Llevará protesta } \\
\text { de expansionis- } \\
\text { mo nicaragüense } \\
\text { ante la ONU. }\end{array}$ & $\begin{array}{l}\text { Alertar a la región } \\
\text { americana sobre } \\
\text { los desequilibrios } \\
\text { ocasionados por } \\
\text { Nicaragua. }\end{array}$ & $\begin{array}{l}\text { Legitimar posición } \\
\text { costarricense en el } \\
\text { conflicto y desvirtuar } \\
\text { imagen nicaragüense, } \\
\text { internacionalmente. }\end{array}$ \\
\hline $\begin{array}{l}\text { Enrique Castillo } \\
\text { (actor) }\end{array}$ & $\begin{array}{l}\text { Señala que } \\
\text { las acciones } \\
\text { de Nicaragua } \\
\text { generan ines- } \\
\text { tabilidad en la } \\
\text { región (compra } \\
\text { de armamento } \\
\text { y reclamo de } \\
\text { territorio). }\end{array}$ & $\begin{array}{l}\text { Indicar las malas } \\
\text { intenciones de Nica- } \\
\text { ragua, y los peligros } \\
\text { que esta representa a } \\
\text { la paz de la región. }\end{array}$ & $\begin{array}{l}\text { Desvirtuar gobierno } \\
\text { de Nicaragua regio- } \\
\text { nalmente, con el fin de } \\
\text { encontrar apoyo sobre } \\
\text { posición de CR en la } \\
\text { región (legitimar) }\end{array}$ \\
\hline $\begin{array}{l}\text { Daniel Ortega } \\
\text { (receptor) }\end{array}$ & $\begin{array}{l}\text { Señalado de ser } \\
\text { el responsable } \\
\text { de los desequili- } \\
\text { brios indicados. }\end{array}$ & $\begin{array}{l}\text { Deslegitimar las } \\
\text { acciones de Ortega } \\
\text { en los conflictos } \\
\text { existentes con CR. }\end{array}$ & $\begin{array}{l}\text { Generar apatía contra } \\
\text { el mandatario en la } \\
\text { opinión pública. }\end{array}$ \\
\hline $\begin{array}{l}\text { Ban Ki-Moon } \\
\text { (Secretario ONU) } \\
\text { (receptor) }\end{array}$ & $\begin{array}{l}\text { Receptor de la } \\
\text { protesta. }\end{array}$ & $\begin{array}{l}\text { Llevar el caso } \\
\text { ante una autoridad } \\
\text { competente interna- } \\
\text { cionalmente. }\end{array}$ & $\begin{array}{l}\text { Obtener apoyo por } \\
\text { parte de los Estados } \\
\text { Miembros de la ONU. }\end{array}$ \\
\hline $\begin{array}{l}\text { Juan Manuel } \\
\text { Santos (Presidente } \\
\text { Colombia) (actor) }\end{array}$ & $\begin{array}{l}\text { Apoya protesta } \\
\text { de Chinchilla } \\
\text { ante la ONU. }\end{array}$ & $\begin{array}{l}\text { Evitar posibles } \\
\text { desequilibrios regio- } \\
\text { nales, que afecten } \\
\text { intereses de su país. }\end{array}$ & $\begin{array}{l}\text { Detecta intereses en } \\
\text { peligro, por expansio- } \\
\text { nismo nicaragüense, } \\
\text { por eso da su apoyo a } \\
\text { Costa Rica. }\end{array}$ \\
\hline $\begin{array}{l}\text { Ricardo Marti- } \\
\text { nelli (Presidente } \\
\text { Panamá) (Actor) }\end{array}$ & $\begin{array}{l}\text { Apoya protesta } \\
\text { de Chinchilla } \\
\text { ante la ONU. }\end{array}$ & $\begin{array}{l}\text { Evitar posibles } \\
\text { desequilibrios regio- } \\
\text { nales, que afecten } \\
\text { intereses de su país. }\end{array}$ & $\begin{array}{l}\text { Detecta intereses en } \\
\text { peligro, por expansio- } \\
\text { nismo nicaragüense, } \\
\text { por eso da su apoyo a } \\
\text { Costa Rica. }\end{array}$ \\
\hline
\end{tabular}

Fuente: Elaboración propia según datos de Mata (2013). 
Tabla 3.4

Grupos de conceptos equivalentes por categoría y la idea que sostienen en conjunto.

\begin{tabular}{|c|c|c|}
\hline Categoría & $\begin{array}{c}\text { Grupo de conceptos } \\
\text { equivalentes }\end{array}$ & $\begin{array}{c}\text { Contextos temáticos donde son } \\
\text { utilizados }\end{array}$ \\
\hline A & Terri & $\begin{array}{l}\text { Costa Rica ve en peligro la jurisdic- } \\
\text { ción sobre su propio territorio. }\end{array}$ \\
\hline $\mathrm{B}$ & Prot-Quej-Recla-Lit-Inva & $\begin{array}{l}\text { CR lleva su protesta a la ONU, ante } \\
\text { el litigio con Nicaragua y señala } \\
\text { invasión. }\end{array}$ \\
\hline $\mathrm{C}$ & Expan-Arma-Ejer & $\begin{array}{l}\text { Nicaragua busca expandirse, por eso } \\
\text { fortalece su armamento y ejército. }\end{array}$ \\
\hline $\mathrm{D}$ & Inte-Diplo & $\begin{array}{l}\text { CR busca defender sus intereses } \\
\text { territoriales, por la vía diplomática. }\end{array}$ \\
\hline
\end{tabular}

Fuente: Elaboración propia según datos de Mata (2013).

\section{Tabla 3.5}

Frases que sostienen una idea implícita que legitima las categorías

\begin{tabular}{lll}
\hline \multicolumn{1}{c}{ Frases } & \multicolumn{1}{c}{ Variable } & Categoría \\
\hline "Nicaragua se está armando, lo ha dicho & Acusación & A \\
públicamente; sabemos que tiene un & Armamento militar & C \\
arsenal de misiles, de manera que esto es & Defensa & A \\
algo que altera el balance de la región". & Estrategia & A \\
\hline
\end{tabular}

Fuente: Elaboración propia según datos de Mata (2013). 


\section{Documento 4: "Nicaragua pide a la CIJ aplicar medidas cautelares en frontera con Costa Rica"4}

\section{Tabla 4.1}

Frecuencia con que aparecen los actores

\begin{tabular}{lc}
\hline \multicolumn{1}{c}{ Actor } & Frecuencia simple observada \\
\hline Carlos Argüello (Representante Nicaragua ante CIJ) & 4 \\
CIJ & 4 \\
\hline
\end{tabular}

Fuente: Elaboración propia con base en datos de La Nación (17 de octubre del 2013).

\section{Tabla 4.2}

Frecuencia con que aparecen palabras claves y frecuencia con que se legitiman las categorías del neorrealismo de acuerdo con la idea que sostiene cada palabra.

\begin{tabular}{llccccc}
\hline \multicolumn{1}{c}{ Variable } & Código & $\begin{array}{c}\text { Frecuencia } \\
\text { observada }\end{array}$ & & \multicolumn{2}{c}{ Categorías } \\
& & & A & B & C & D \\
\cline { 4 - 8 } Medidas cautelares & Mecau & 5 & & I-I-I- & \\
Daños & Dañ & 3 & & I-I & \\
Fronterizo & Fronte & 2 & I-I & & & \\
Acusa & Acu & 2 & & I-I & \\
Disputa & Dis & 1 & & I & & \\
Invadir & Inva & 1 & & I & & \\
Reclama & Recla & 1 & & I & & \\
Denuncia & Denun & 2 & & I-I & & \\
Demanda & Deman & 1 & & I & & \\
Total & & $\mathbf{1 8}$ & $\mathbf{2}$ & $\mathbf{1 6}$ & $\mathbf{0}$ & $\mathbf{0}$ \\
\hline
\end{tabular}

Fuente: Elaboración propia con base en datos de La Nación (17 de octubre del 2013).

4 La Nación. (17 de octubre del 2013). Nicaragua pide a CIJ aplicar medidas cautelares en frontera con Costa Rica. Costa Rica. Recuperado de: http://www.lanacion.com.co/index.php/ internacional/item/224181-nicaragua-pide-a-la-cij-aplicar-medidas-cautelares-en-frontera-concosta-rica 


\section{Categorías:}
A. Los Estados son los actores centrales, son racionales, autónomos y unitarios.
B. La naturaleza de su vida política internacional es conflictiva.
C. La motivación es el poder, la seguridad y la supervivencia.
D. Las alianzas existen para que cada Estado alcance sus propios intereses.

\section{Tabla 4.3}

Intenciones de los actores

\begin{tabular}{|c|c|c|c|}
\hline Actores & Acción & Objeto de la acción & Síntesis \\
\hline $\begin{array}{l}\text { Carlos } \\
\text { Argüello } \\
\text { (Represen- } \\
\text { tante de } \\
\text { Nicaragua } \\
\text { ante CIJ) } \\
\text { (Actor) }\end{array}$ & $\begin{array}{l}\text { Pide medidas } \\
\text { cautelares contra CR } \\
\text { ante la CIJ, por los } \\
\text { daños ocasionados } \\
\text { por construcción de } \\
\text { carretera fronteriza. }\end{array}$ & $\begin{array}{l}\text { Responsabilizar a CR } \\
\text { de daños fronterizos } \\
\text { y deslegitimar su } \\
\text { imagen internacional- } \\
\text { mente. }\end{array}$ & $\begin{array}{l}\text { Encontrar apoyo } \\
\text { internacional de altas } \\
\text { autoridades como la } \\
\text { CIJ, para legitimar su } \\
\text { posición y deslegiti- } \\
\text { mar acciones costarri- } \\
\text { censes. }\end{array}$ \\
\hline $\begin{array}{l}\text { CIJ(Actor y } \\
\text { receptor) }\end{array}$ & $\begin{array}{l}\text { Dicta medidas cau- } \\
\text { telares en el } 2011, \\
\text { para que ambos } \\
\text { países se retiren de } \\
\text { isla Portillos. } \\
\text { 2013: Recibe denun- } \\
\text { cia de Nicaragua, } \\
\text { por daños ambienta- } \\
\text { les causados por CR }\end{array}$ & $\begin{array}{l}\text { Responsabiliza a } \\
\text { ambos países de las } \\
\text { diferencias y los } \\
\text { litigios fronterizos } \\
\text { existentes. } \\
\text { Nicaragua busca una } \\
\text { respuesta favorable a } \\
\text { sus intereses, y espera } \\
\text { medidas cautelares } \\
\text { para CR }\end{array}$ & $\begin{array}{l}\text { Investiga y analiza } \\
\text { caso, y dicta medidas } \\
\text { que busquen pacificar } \\
\text { el conflicto. CIJ } \\
\text { se expone como el } \\
\text { organismo competente } \\
\text { para resolver este tipo } \\
\text { de conflictos, para } \\
\text { Nicaragua. }\end{array}$ \\
\hline
\end{tabular}

Fuente: Elaboración propia con base en datos de La Nación (17 de octubre del 2013). 


\section{Tabla 4.4}

Grupos de conceptos equivalentes por categoría y la idea que sostienen en conjunto.

\begin{tabular}{|c|c|c|}
\hline Categoría & $\begin{array}{l}\text { Grupo de conceptos } \\
\text { equivalentes }\end{array}$ & $\begin{array}{c}\text { Contextos temáticos donde son } \\
\text { utilizados }\end{array}$ \\
\hline A & Front & $\begin{array}{l}\text { Nicaragua expone daños causados } \\
\text { por CR a la frontera. }\end{array}$ \\
\hline B & $\begin{array}{l}\text { Mecau-Dañ-Acu-Dip-Inva- } \\
\text { Denun-Recla-Deman. }\end{array}$ & $\begin{array}{l}\text { Se denuncia a CR ante CIJ, } \\
\text { reclamando daños ambientales e } \\
\text { invasión, pide medidas cautelares. }\end{array}$ \\
\hline $\mathrm{C}$ & (ausencia de conceptos) & ---------. \\
\hline $\mathrm{D}$ & (ausencia de conceptos) & ----------- \\
\hline
\end{tabular}

Fuente: Elaboración propia con base en datos de La Nación (17 de octubre del 2013).

\section{Tabla 4.5}

Frases que sostienen una idea implícita que legitima las categorías

\begin{tabular}{ccc}
\hline Frases & Variable & Categoría \\
\hline "El gobierno de San José acusa a & & \\
$\begin{array}{l}\text { Nicaragua de no respetar esa orden } \\
\text { de CIJ" }\end{array}$ & Conflicto-acusación-irrespeto. & B \\
\hline
\end{tabular}

Fuente: Elaboración propia con base en datos de La Nación (17 de octubre del 2013). 


\section{Documento 5: "Costa Rica podría reafirmar fuerzas armadas, afirman sandinistas" 5}

\section{Tabla 5.1}

Frecuencia con que aparecen los actores

\begin{tabular}{lc}
\hline \multicolumn{1}{c}{ Actores } & Frecuencia simple observada \\
\hline Jacinto Suárez ( Secretario de RI en Nicaragua) & 3 \\
Enrique Castillo & 2 \\
Laura Chichilla & 2 \\
CIJ & 4 \\
\hline
\end{tabular}

Fuente: Elaboración propia con base en datos tomados de La Nación (24 de septiembre del 2013).

5 La Nación. (24 de septiembre del 2013). Costa Rica podría restablecer fuerzas armadas, afirma sandinista. Recuperado de: http://www.nacion.com/mundo/centroamerica/Nicaragua-Daniel_ Ortega-conflicto_fronterizo-Costa_Rica_0_1368063404.html 

políticamente conflictivo para Costa Rica?

\section{Tabla 5.2}

Frecuencia con que aparecen palabras claves y frecuencia con que se legitiman las categorías del neorrealismo de acuerdo con la idea que sostiene cada palabra.

\begin{tabular}{|c|c|c|c|c|c|c|}
\hline \multirow[t]{2}{*}{ Variable } & \multirow[t]{2}{*}{ Código } & Frecuencia observada & \multicolumn{4}{|c|}{ Categorías } \\
\hline & & & A & B & $\mathrm{C}$ & $\mathrm{D}$ \\
\hline Medidas Cautelares & mecau & 1 & & I & & \\
\hline Daños & Dañ & 1 & & I & & \\
\hline Frontera & Fron & 1 & I & & & \\
\hline Acusaciones & Acu & 3 & & I-I-I & & \\
\hline Defensa & Def & 1 & I & & & \\
\hline Invasión & Inva & 1 & & I & & \\
\hline Reclaman & Recla & 1 & & I & & \\
\hline Denuncia & Denun & 1 & & I & & \\
\hline Demanda & Deman & 2 & & I-I & & \\
\hline Expansionismo & Expan & 1 & & & I & \\
\hline Irrespeto & Irre & 1 & & I & & \\
\hline Integridad territorial & Interri & 1 & I & & & \\
\hline Armarse & arma & 1 & & & I & \\
\hline Protesta & Prot & 1 & & I & & \\
\hline Fuerzas Armadas & Fuarma & 2 & & & I-I & \\
\hline Armamentismo & Arma & 1 & & & I & \\
\hline Litigio & Lit & 1 & & I & & \\
\hline Ejército & Ejer & 1 & & & I & \\
\hline Enemigo & Ene & 2 & & I-I & & \\
\hline Agresión & Agre & 2 & & I-I & & \\
\hline Derecho Internacional & Deinter & 3 & & & & I-I-I \\
\hline Engañar & Eng & 1 & & I & & \\
\hline Militarizar & Mili & 2 & $\mathrm{I}-\mathrm{I}$ & & I & \\
\hline Estrategia & Estra & 1 & I & & & \\
\hline Relaciones bilaterales & Rebi & 2 & & & & $\mathrm{I}-\mathrm{I}$ \\
\hline Territorio & Terri & 3 & I-I-I & & & \\
\hline Interés & Inter & 1 & & & & I \\
\hline Total & & 40 & 9 & 18 & 7 & 6 \\
\hline
\end{tabular}

Fuente: Elaboración propia con base en datos tomados de La Nación (24 de septiembre del 2013). 


\section{Categorías:}
A. Los Estados son los actores centrales, son racionales, autónomos y unitarios.
B. La naturaleza de su vida política internacional es conflictiva.
C. La motivación es el poder, la seguridad y la supervivencia.
D. Las alianzas existen para que cada Estado alcance sus propios intereses.

\section{Tabla 5.3}

Intenciones de los actores

\begin{tabular}{|c|c|c|c|}
\hline Actores & Acción & Objeto de la acción & Síntesis \\
\hline $\begin{array}{l}\text { Jacinto } \\
\text { Suárez } \\
\text { (Secretario } \\
\text { de RI en } \\
\text { Nicaragua) } \\
\text { (Actor) }\end{array}$ & $\begin{array}{l}\text { Señala que detrás de } \\
\text { las acusaciones de CR } \\
\text { existe el interés de este } \\
\text { de restablecer las fuer- } \\
\text { zas armadas.Rechaza } \\
\text { agresión hacia CR y } \\
\text { considera a Nicaragua } \\
\text { partidaria del Derecho } \\
\text { Internacional. }\end{array}$ & $\begin{array}{l}\text { Exponer que CR actúa } \\
\text { con malas intencio- } \\
\text { nes ante la opinión } \\
\text { pública, y que utiliza } \\
\text { las acusaciones contra } \\
\text { Nicaragua, como } \\
\text { estrategia para militari- } \\
\text { zarse.Exponer imagen } \\
\text { pacífica de Nicaragua. }\end{array}$ & $\begin{array}{l}\text { Utiliza el argumento } \\
\text { de que CR desea mi- } \\
\text { litarizarse para justi- } \\
\text { ficar las acusaciones } \\
\text { de estos hacia su } \\
\text { país, y no realmente } \\
\text { porque Nicaragua } \\
\text { esté actuando mal } \\
\text { ni causando daños o } \\
\text { agresiones a CR }\end{array}$ \\
\hline $\begin{array}{l}\text { Enrique } \\
\text { Castillo } \\
\text { (Receptor) }\end{array}$ & $\begin{array}{l}\text { Señalado de haberse } \\
\text { referido a la militari- } \\
\text { zación de CR por parte } \\
\text { de Nicaragua. }\end{array}$ & $\begin{array}{l}\text { Nicaragua busca } \\
\text { legitimar su discurso, } \\
\text { al desvirtuar a canciller } \\
\text { costarricense y su } \\
\text { "falta de transparencia } \\
\text { en sus declaraciones". }\end{array}$ & $\begin{array}{l}\text { Nicaragua busca ar- } \\
\text { gumentar su retórica, } \\
\text { al señalar a Castillo } \\
\text { como partidario } \\
\text { de militarización } \\
\text { costarricense. }\end{array}$ \\
\hline $\begin{array}{l}\text { Laura } \\
\text { Chichilla } \\
\text { (Actor) }\end{array}$ & $\begin{array}{l}\text { Acusa a Nicaragua } \\
\text { ante la ONU de } \\
\text { expansionismo. }\end{array}$ & $\begin{array}{l}\text { Exponer internacional- } \\
\text { mente la violación de } \\
\text { soberanía de Nicaragua } \\
\text { hacia CR y el peligro } \\
\text { de esas políticas para la } \\
\text { región. }\end{array}$ & $\begin{array}{l}\text { Desvirtúa imagen } \\
\text { internacional de } \\
\text { Nicaragua, a la vez } \\
\text { que busca apoyo } \\
\text { externo para su país, } \\
\text { mediante el discurso. }\end{array}$ \\
\hline CIJ & $\begin{array}{l}\text { Tramita en un solo } \\
\text { caso denuncias por } \\
\text { litigios territoriales } \\
\text { desde el } 2010 .\end{array}$ & $\begin{array}{l}\text { Se le ha dado compe- } \\
\text { tencia y potestad para } \\
\text { dar fin al conflicto. }\end{array}$ & $\begin{array}{l}\text { Organismo que para } \\
\text { ambos países es } \\
\text { competente, para } \\
\text { resolver el conflicto. }\end{array}$ \\
\hline
\end{tabular}

Fuente: Elaboración propia con base en datos tomados de La Nación (24 de septiembre del 2013). 


\section{Tabla 5.4}

Grupos de conceptos equivalentes por categoría y la idea que sostienen en conjunto.

\begin{tabular}{|c|c|c|}
\hline Categoría & $\begin{array}{l}\text { Grupo de conceptos } \\
\text { equivalentes }\end{array}$ & Contextos temáticos donde son utilizados \\
\hline A & Fron-Def- Interri-Estra & $\begin{array}{l}\text { La CIJ tramita solo un caso de demanda } \\
\text { de CR hacia Nicaragua, por violación de } \\
\text { fronteras e integridad territorial.Nicaragua } \\
\text { considera que dichas acusaciones son estrate- } \\
\text { gia costarricense. }\end{array}$ \\
\hline B & $\begin{array}{l}\text { Mecau-Dañ-Acu-Inva- } \\
\text { Recla-Denun-Deman-Irre- } \\
\text { Prot- Lit- Ene-Agre-Eng- } \\
\text { Mili }\end{array}$ & $\begin{array}{l}\text { CR pide medidas cautelares ante Nicaragua } \\
\text { por invasión. }\end{array}$ \\
\hline $\mathrm{C}$ & Expan-Fuarma-Arma-Ejer & $\begin{array}{l}\text { CR señala a Nicaragua de expansionista. Los } \\
\text { nicaragüenses señalan que es plan de CR } \\
\text { para militarizarse. }\end{array}$ \\
\hline $\mathrm{D}$ & Deinter-Rebi-Inter-Diplo & $\begin{array}{l}\text { Nicaragua señala que CR en lugar de } \\
\text { mentir con la militarización, debería de } \\
\text { utilizar la diplomacia. Además, se expone } \\
\text { que el litigio ha desgastado las relaciones } \\
\text { bilaterales entre ambos. }\end{array}$ \\
\hline
\end{tabular}

Fuente: Elaboración propia con base en datos tomados de La Nación (24 de septiembre del 2013).

\section{Tabla 5.5}

Frases que sostienen una idea implícita que legitima las categorías

\begin{tabular}{lcc}
\hline \multicolumn{1}{c}{ Frases } & Variable & Categoría \\
\hline "Chinchilla aseguró que Costa Rica es un & & \\
"firme creyente" del derecho internacional, una & & \\
actitud que contrasta con el "irrespeto absoluto" & Acusación & A \\
de Nicaragua a las normas más elementales de & & \\
la conducta y convivencia entre los Estados". & & \\
\hline
\end{tabular}

Fuente: Elaboración propia con base en datos tomados de La Nación (24 de septiembre del 2013). 
Parte 2: Tablas por total de documentos: análisis general

\section{Actores en totalidad de documentos}

\section{Tabla 1}

Frecuencia con que son mencionados los actores en la totalidad de documentos

\begin{tabular}{lc}
\hline \multicolumn{1}{c}{ Actores } & Frecuencia simple \\
\hline Laura Chinchilla & 6 \\
Enrique Castillo & 10 \\
Daniel Ortega & 8 \\
Ban Ki-Moon & 1 \\
CIJ & 15 \\
Moisés Hallenslevens & 1 \\
Juan Manuel Santos & 1 \\
Ricardo Martinelli & 1 \\
Carlos Argüello & 4 \\
Jacinto Suarez & 3 \\
Total & 50 \\
\hline
\end{tabular}

Fuente: Elaboración propia a partir de la información de los cinco artículos del diario La Nación, citados anteriormente.

Basado en cuadro 1, de los documentos 1, 2, 3, 4, y 5 de la parte I. 


\subsection{Descripción en términos porcentuales}

Figura 1. Porcentaje de actores del conflicto en la totalidad de artículos.

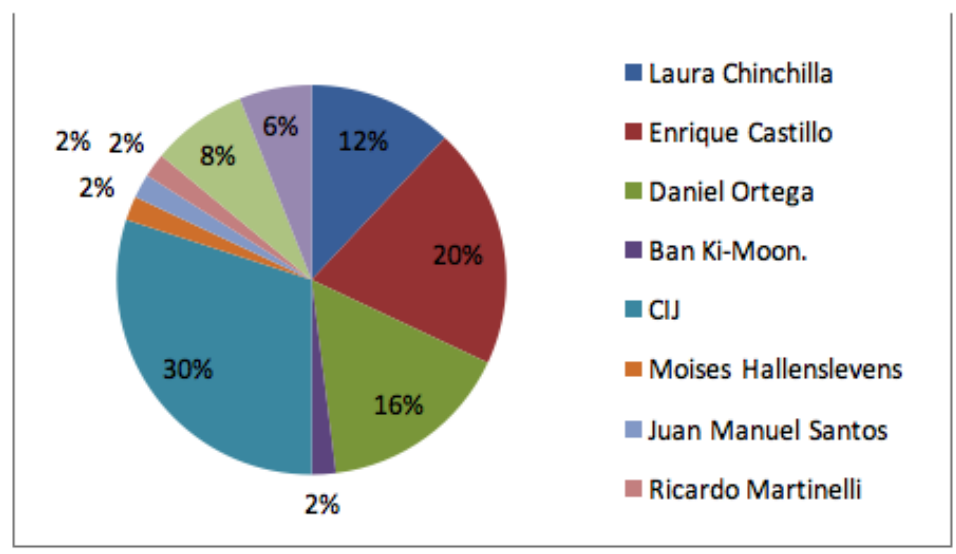

Fuente: Elaboración propia a partir de la información de los cinco artículos del diario La Nación, citados anteriormente.

\section{Intenciones de los actores}

\section{Tabla 2}

Posiciones de los actores costarricenses

\begin{tabular}{lccccc}
\hline \multicolumn{1}{c}{ Actores } & \multicolumn{5}{c}{ Documentos } \\
\hline $\begin{array}{l}\text { Laura } \\
\text { Chinchilla }\end{array}$ & D & 2 & 3 & 4 & 5 \\
$\begin{array}{l}\text { Enrique } \\
\text { Castillo }\end{array}$ & A & D & C & D & C \\
\hline
\end{tabular}

Fuente: Elaboración propia a partir de la información de los cinco artículos del diario La Nación, citados anteriormente. Basados en Cuadro 3, de documentos 1, 2, 3, 4 y 5. 


\subsection{Posiciones}
A. Ataca la posición de la contraparte, sin buscar consenso.
B. Busca consenso de forma directa con la contraparte.
C. Acuden a organismos internacionales.
D. No emiten criterio dentro del documento.

\subsection{Descripción de la tabla en términos porcentuales}

Figura 2. Acciones de Laura Chinchilla

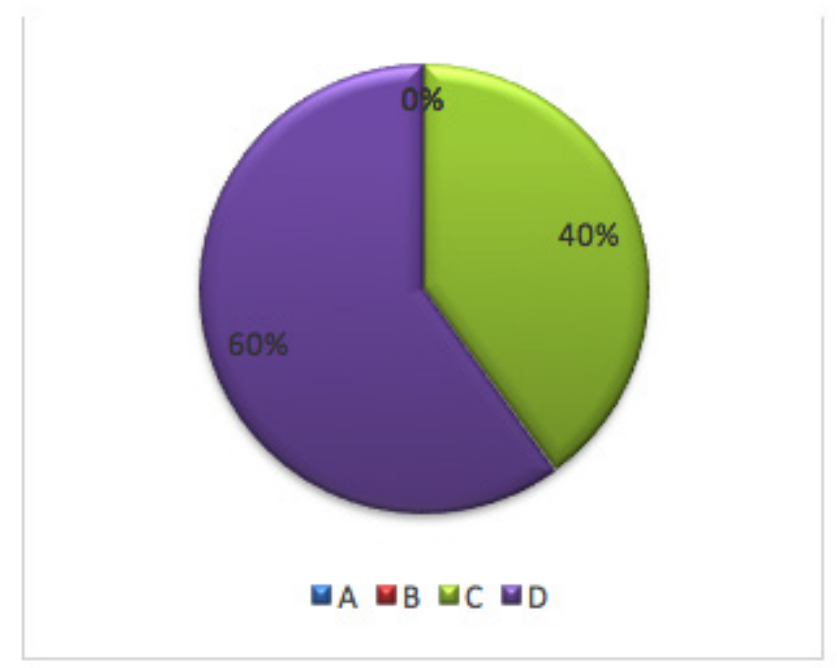

Fuente: Elaboración propia a partir de la información de los cinco artículos del diario La Nación, citados anteriormente.

\subsection{Clasificación}
A. Ataca la posición nicaragüense, sin buscar consenso $=0 \%$
B. Busca consenso de forma directa con la contraparte $=0 \%$
C. Acuden a organismos internacionales $=40 \%$
D. No emiten criterio dentro de los documentos $=60 \%$ 


\subsection{Descripción}

- De las veces que se expone el criterio de la mandataria dentro de los documentos ( $40 \%$ de los documentos), el 100\% acude a organismos internacionales para hacer frente al conflicto, según los documentos del diario La Nación, aquí analizados.

Figura 3. Acciones de Enrique Castillo en términos porcentuales.

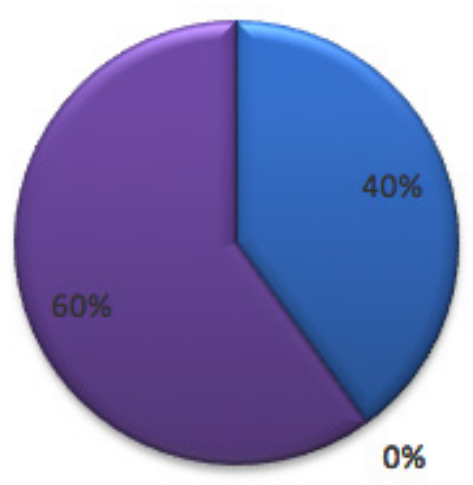

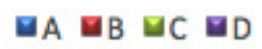

Fuente: Elaboración propia a partir de la información de los cinco artículos del diario La Nación, citados anteriormente.

\subsection{Clasificación}
A. Ataca la posición del nicaragüense, sin buscar consenso $=40 \%$
B. Busca consenso de forma directa con la contraparte $=0 \%$
C. Acuden a organismos internacionales $=0 \%$
D. No emiten criterio dentro del documento $=60 \%$ 


\subsection{Descripción}

No se expone el criterio del Canciller, en el $60 \%$ de los documentos; no obstante, cuando sí se expone ( $40 \%$ de los documentos) en el 100\% de sus declaraciones ataca la posición nicaragüense.

\section{Actores nicaragüenses}

Tabla 3

Posiciones de los actores nicaragüenses

\begin{tabular}{lccccc}
\hline \multicolumn{1}{c}{ Actores } & \multicolumn{5}{c}{ Documentos } \\
\hline & $\mathbf{1}$ & $\mathbf{2}$ & $\mathbf{3}$ & $\mathbf{4}$ & $\mathbf{5}$ \\
\cline { 2 - 6 } Daniel Ortega & $\mathrm{D}$ & $\mathrm{C}-\mathrm{A}$ & $\mathrm{D}$ & $\mathrm{D}$ & $\mathrm{D}$ \\
Moisés Hallenlevens (Vicepresidente) & $\mathrm{A}$ & $\mathrm{D}$ & $\mathrm{D}$ & $\mathrm{D}$ & $\mathrm{D}$ \\
Jacinto Suárez (Secretario RI) & $\mathrm{D}$ & $\mathrm{D}$ & $\mathrm{D}$ & $\mathrm{D}$ & $\mathrm{A}$ \\
Carlos Argüello (Representante ante CIJ) & $\mathrm{D}$ & $\mathrm{D}$ & $\mathrm{D}$ & $\mathrm{C}$ & $\mathrm{D}$ \\
\hline
\end{tabular}

Fuente: Elaboración propia a partir de la información de los cinco artículos del diario La Nación, citados anteriormente.

\subsection{Posiciones:}
A. Ataca la posición de la contraparte, sin buscar consenso.
B. Busca consenso de forma directa con la contraparte.
C. Acuden a organismos internacionales.
D. No emiten criterio dentro del documento. 


\subsection{Descripción en términos porcentuales}

Figura 4. Acciones de Daniel Ortega.

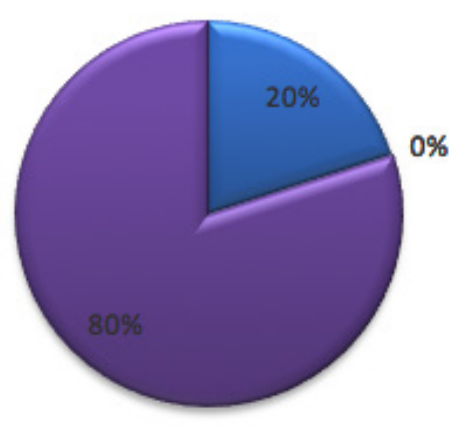

$\boldsymbol{\square} \boldsymbol{A} \square \mathrm{B} \boldsymbol{\mathrm { D }}$

Fuente: Elaboración propia a partir de la información de los cinco artículos del diario La Nación, citados anteriormente.

Figura 5. Acciones del Vicepresidente.

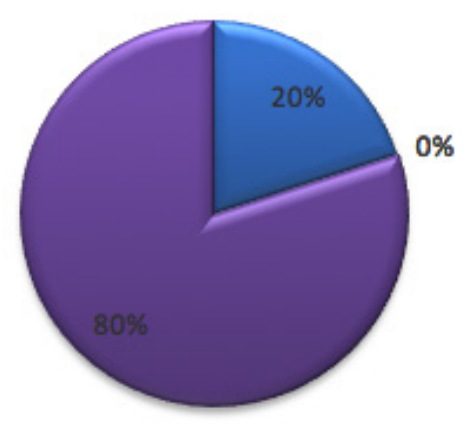

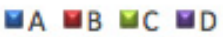

Fuente: Elaboración propia a partir de la información de los cinco artículos del diario La Nación, citados anteriormente. 
Figura 6. Acciones del jefe de Relaciones Internacionales.

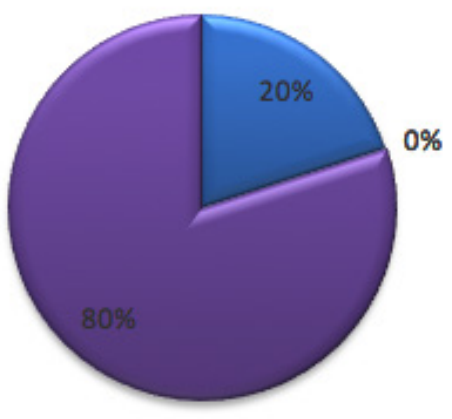

$\mathbf{A} \square \mathrm{B} \square \mathrm{C} \boldsymbol{\mathrm { D }}$

Fuente: Elaboración propia a partir de la información de los cinco artículos del diario La Nación, citados anteriormente.

Figura 7. Acciones del representante ante la CIJ.

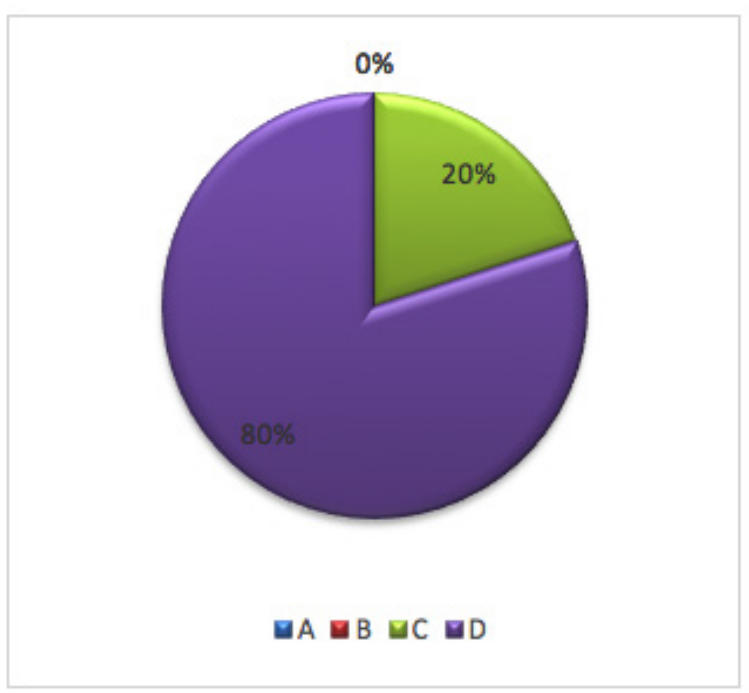

Fuente: Elaboración propia a partir de la información de los cinco artículos del diario La Nación, citados anteriormente. 
3.3 Descripción de gráficas: El $75 \%$ de los actores nicaragüenses no emite criterios sobre el conflicto un $80 \%$ de las veces, y el $100 \%$ de las veces que se refieren al conflicto, ataca la posición costarricense.

Mientras el $25 \%$ de actores, igualmente el $80 \%$ de las veces no emite criterio, pero en el $100 \%$ que se refiere al conflicto, menciona que acudirá a organismos internacionales.

\section{Categorías del neorrealismo que se legitima en la totalidad de documentos}

\section{Tabla 4}

Frecuencia en que las categorías se legitiman de acuerdo con el número de palabras que la sostienen.

\begin{tabular}{|c|c|c|c|c|c|}
\hline \multirow[t]{2}{*}{ Categorías } & \multicolumn{4}{|c|}{ Documentos } & \multirow[t]{2}{*}{ Total } \\
\hline & 1 & 2 & 3 & 4 & \\
\hline $\mathbf{A}$ & 9 & 9 & 1 & 2 & 21 \\
\hline B & 5 & 6 & 8 & 16 & 37 \\
\hline $\mathrm{C}$ & 4 & 4 & 4 & 0 & 12 \\
\hline D & 1 & 0 & 2 & 0 & 3 \\
\hline
\end{tabular}

Fuente: Elaboración propia a partir de la información de los cinco artículos del diario La Nación, citados anteriormente.

Basados en cuadro 2, de documentos 1, 2, 3, 4 y 5. 


\subsection{Descripción porcentual}

Figura 8. Frecuencia con que se legitima una categoría en la totalidad de documentos en porcentaje.

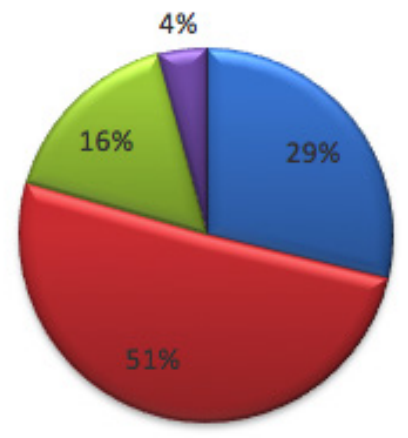

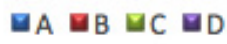

Fuente: Elaboración propia a partir de la información de los cinco artículos del diario la Nación, citados anteriormente.

\subsection{Descripción de la gráfica}
A. Los Estados son los actores centrales, son racionales, autónomos y unitarios: 29\%.
B. La naturaleza de su vida política internacional es conflictiva: $51 \%$.
C. La motivación es el poder, la seguridad y la supervivencia: $16 \%$.
D. Las alianzas existen para que cada Estado alcance sus propios intereses: 4\%. 


\section{Categorías del neorrealismo y frases implícitas}

Figura 8. Frecuencia en que las categorías del Neorrealismo se legitiman de acuerdo con las frases implícitas detectadas en los documentos.

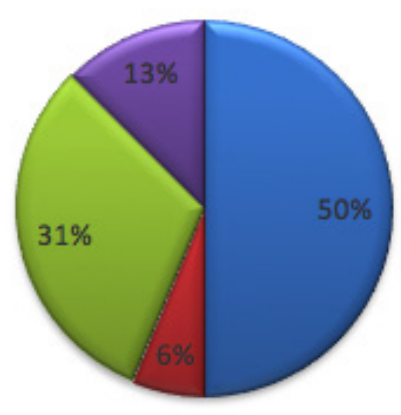

$\nabla \mathrm{A} \square \mathrm{B} \boldsymbol{\mathrm { D }}$

Fuente: Elaboración propia a partir de la información de los cinco artículos del diario la Nación, citados anteriormente. Basados en cuadro 4, de documentos 1, 2, 3, 4 y 5.

\subsection{Descripción de la gráfica}
A. Los Estados son los actores centrales, son racionales, autónomos y unitarios: 50\%.
B. La naturaleza de su vida política internacional es conflictiva: $6 \%$.
C. La motivación es el poder, la seguridad y la supervivencia: $31 \%$.
D. Las alianzas existen para que cada Estado alcance sus propios intereses: 13\%. 


\section{Conceptos de cada categoría y el contexto temático}

Figura 10. Frecuencia de contextos temáticos, según conceptos equivalentes de cada categoría

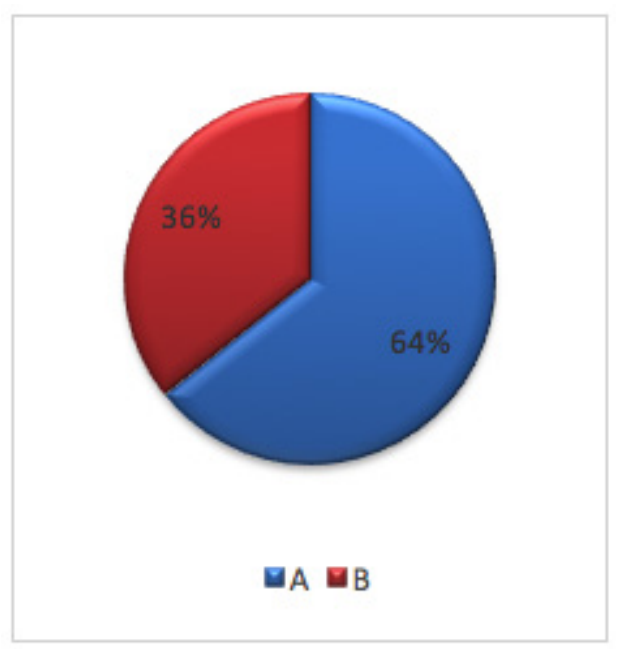

Fuente: Elaboración propia a partir de la información de los cinco artículos del diario la Nación, citados anteriormente.

Basados en cuadro 5, de documentos 1, 2, 3, 4 y 5.

\subsection{Contextos}
A. Atacan contraparte sin buscar consenso.
B. Buscan acudir a un organismo Internacional.

\subsection{Descripción de la gráfica}

En los documentos analizados, aproximadamente un $64 \%$ de las veces se ataca a la contraparte (Nicaragua) sin que se quiera buscar algún tipo de consenso. Por su parte, un $36 \%$ de las veces Costa Rica presume de acudir a organismos internacionales para hacer frente al conflicto. 


\section{Legitimidad de la competencia de la corte internacional de justicia}

Figura 11. Competencia de la corte.

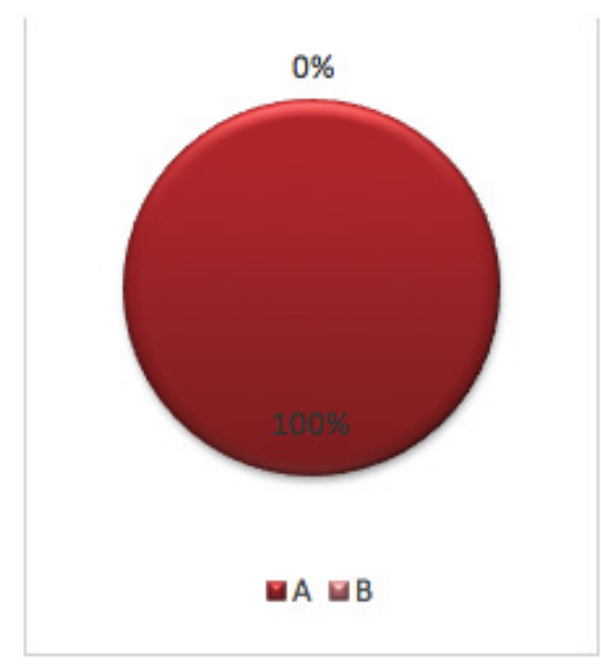

Fuente: Elaboración propia a partir de la información de los cinco artículos del diario la Nación, citados anteriormente.

\section{Descripción de la gráfica:}
A. Competencia de la CIJ.
B. Incompetencia de la CIJ.

Se reconoce en un $100 \%$ de las veces en que la Corte es mencionada en los documentos, donde tiene competencia en el conflicto territorial Costa Rica-Nicaragua. 


\section{Intenciones nicaragüenses detectadas en el conflicto, en la totalidad de documentos}

\subsection{Categorías de intenciones}

A. Nicaragua cuenta con plan expansionista, incluye: reclamo de Guanacaste, apoderamiento de territorios de ultramar, motivación de desarrollo económico: $50 \%$.

B. Los documentos exponen que Nicaragua desvirtúa la imagen de Gobierno costarricense, al expresarse del mal asesoramiento de este: $16 \%$.

C. Se expone la naturaleza conflictiva de Ortega: $17 \%$.

D. Ortega es un desinformante: controla medios de comunicación de su país.

E. Ortega como amenaza para la región, pues representa un desequilibrio de esta: $17 \%$.

Figura 12. Intenciones nicaragüenses.

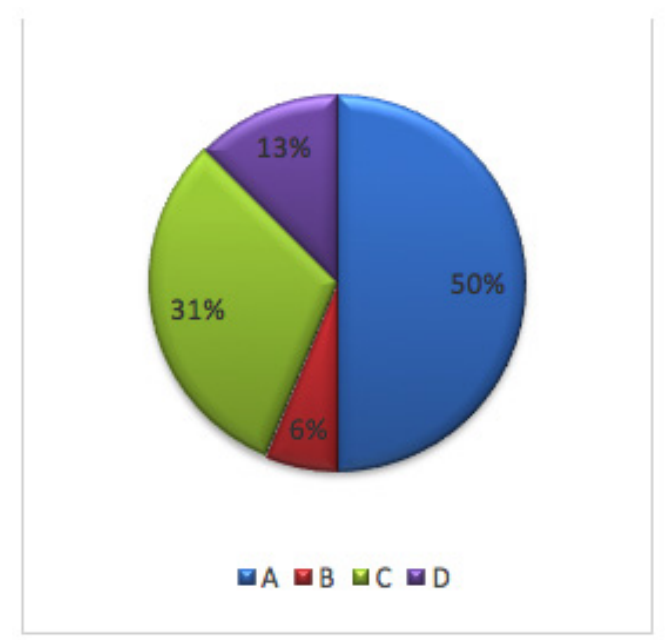

Fuente: Elaboración propia a partir de la información de los cinco artículos del diario la Nación, citados anteriormente. 


\section{Intenciones de la política expansionista nicaragüense}

\subsection{Descripción de gráfica}

A. Crecimiento territorial: Territorio de Guanacaste, zonas marítimas: $67 \%$

B. Crecimiento económico: Explotación de áreas de ultramar: 33\%

Figura 13. Intereses presentes en política expansionista

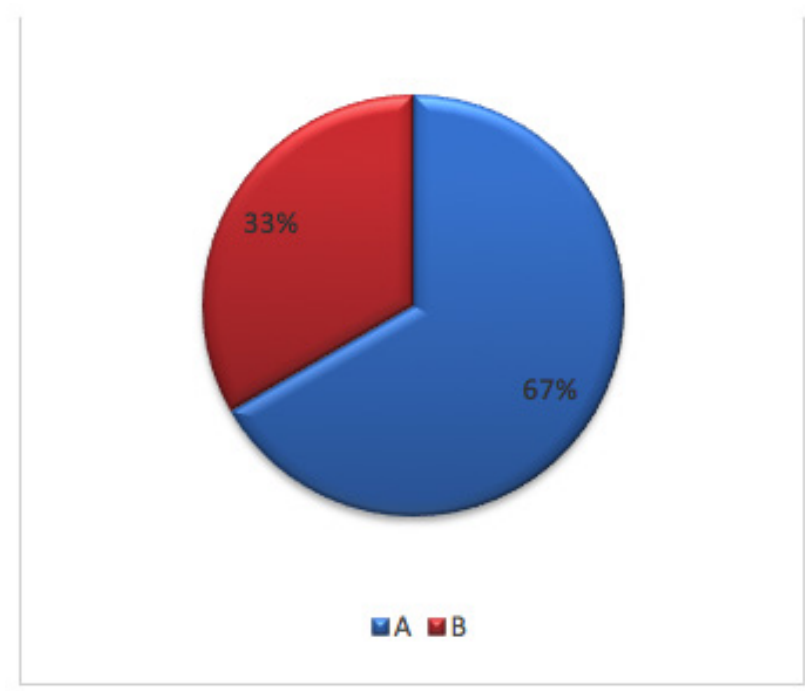

Fuente: Elaboración propia a partir de la información de los cinco artículos del diario la Nación, citados anteriormente.

Basado en cuadro 3, documentos 1, 2, 3, 4 y 5 de la parte I. 